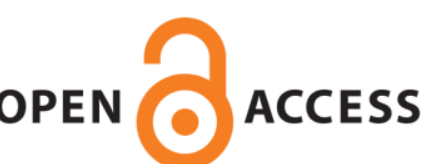

UWS Academic Portal

\title{
Effect of humidification of reactive gases on the performance of a proton exchange membrane fuel cell
}

Wilberforce, Tabbi; ljaodola, O.; Khatib, F. N.; Ogungbemi, E. O.; El Hassan, Zaki;

Thompson, James; Olabi, A.G.

Published in:

Science of the Total Environment

DOI:

10.1016/j.scitotenv.2019.06.397

Published: 20/10/2019

Document Version

Peer reviewed version

Link to publication on the UWS Academic Portal

Citation for published version (APA):

Wilberforce, T., ljaodola, O., Khatib, F. N., Ogungbemi, E. O., El Hassan, Z., Thompson, J., \& Olabi, A. G.

(2019). Effect of humidification of reactive gases on the performance of a proton exchange membrane fuel cell.

Science of the Total Environment, 688, 1016-1035. https://doi.org/10.1016/j.scitotenv.2019.06.397

\section{General rights}

Copyright and moral rights for the publications made accessible in the UWS Academic Portal are retained by the authors and/or other copyright owners and it is a condition of accessing publications that users recognise and abide by the legal requirements associated with these rights.

Take down policy

If you believe that this document breaches copyright please contact pure@uws.ac.uk providing details, and we will remove access to the work immediately and investigate your claim. 
2 Effect of humidification of reactive gases on the performance of a proton exchange membrane fuel cell 3 Tabbi Wilberforce ${ }^{1}$, O. Ijaodola ${ }^{1}$, F.N. Khatib ${ }^{1}$, E.O. Ogungbemi ${ }^{1}$, Zaki El Hassan ${ }^{1}$, James Thompson ${ }^{1}$, A. G. Olabi ${ }^{2,3}$

5 1. Institute of Engineering and Energy Technologies, University of the West of Scotland, United Kingdom

2. Dept. of Sustainable and Renewable Energy Engineering, University of Sharjah, P.O. 11 Box 27272, Sharjah, UAE

3. Mechanical Engineering and Design, Aston University, School of Engineering and Applied Science, Aston Triangle, Birmingham, B4 7ET, UK 
This work studies the impact of water formation on the performance of Proton Exchange Membrane Fuel Cells (PEMFCs). The work examines water management in PEM fuel cells both experimentally and theoretically.

Experiments are conducted using a one stack PEM fuel cell fitted with Nafion membrane to evaluate its performance using both dry and humidified hydrogen and air. Results obtained confirms the importance of fuel humidification in improving the performance of the fuel cell with all levels of humidification producing better performance than that obtained using dry hydrogen or dry air. Experiments using air with 50\% relative humidity indicate drop in the fuel cell performance when comparing the results to those from air with $100 \%$ relative humidity.

The experimental data provides the basis to validate a computation fluid dynamics model for the fuel cell that is used to carry out further studies and conduct a parametric analysis of the fuel cell performance to examine the effects of flow plates designs, flow patterns such as parallel and counter flow and level of humidification on membrane water saturation, flooding, water management, reactants concentrations and overall cell performance by observing parameters such as membrane protonic conductivity, current density, cell voltage and power.

The CFD model studies and compares the use of air and oxygen in PEM fuel cells and the results show that for $100 \%$ relative humidity the performance obtained using pure oxygen is only marginally better than the one obtained when using air. This indicates that it is more beneficial to use air at the right conditions in PEM fuel cells given the cost of pure oxygen as the overall economic balance and the ease of use favour the utilisation of air.

Key words: Humidification, PEM fuel cell, Polarization curve, ANSYS,

\subsection{Introduction.}

The search for new alternative fuel sources continues due the environmental impacts of the use of fossil fuels and their non-sustainable nature as they are being continuously depleted [1]. The high efficiency of proton exchange membrane fuel cells has led researchers and the industry to consider it as a possible replacement of fossil fuel [2,3]. Fuel cells are best described as electrochemical devices that generate power by means of electrochemical reaction of a fuel (hydrogen) and oxidant (air/oxygen) [4]. The environmental effects of the usage of fuel cells are among the key indicators of the viability of this useful technology [5]. They produce no 
harmful gases and hence considered the future of the energy industry. They are considered as the future of the automotive industry and could also be useful in other stationary and portable applications [6]. There are different types of fuel cells and most of them are named according to the electrolyte being used [7]. The last decades have seen the introduction of the Alkaline fuel cell (AFC), Direct Methanol fuel cells (DMFC), Phosphoric Acid fuel cells (PAFC), Molten Carbonate fuel cells (MCFC), Solid Oxide fuel cells (SOFC) and the Proton Exchange membrane fuel cells (PEMFC). The use of Proton Exchange Membrane fuel cells is preferred as they operate at low temperatures ranging from $30^{\circ} \mathrm{C}$ to $70^{\circ} \mathrm{C}$ and have high power density and they are useful for fast start-ups and rapid response to fluctuating demands [8].

The electrolyte of PEM fuel cells is solid polymer which is in the form of solid proton conducting membrane that acts as the electrolyte.

The main parts of the fuel cell are the Membrane electrode assembly (MEA) and the bipolar plates [9]. The membrane electrode assembly is made up of a gas diffusion layer which is porous, a proton exchange membrane and a catalyst layer sandwiched between two plates [9]. The bipolar plate serves as the medium through which the fuel or oxidant travels to the MEA for the electrochemical reaction to occur. The bipolar plates often have different pattern of grooves of flow channels to supply the fuel cell with the gases at both the anode and the cathode. This clearly indicates that an effective design of the bipolar plate will have a direct implication on the performance of the fuel cell. This is because the effective distribution of the fuel and oxidant over the membrane surface and the diffusion to the catalyst layer will enhance the use of the catalyst active sites, which are often platinum catalyst atoms that are dispersed in a layer as part of the MEA. Again, the water management in the fuel cell will be highly improved as by product of the electrochemical reaction will easily exit the cell. Another advantage of an effective flow plate design is the enhanced efficiency of the collection of the electrons [9]. Several investigations have been conducted on the design of the bipolar plate as it contributes to 60 percent of the weight of the fuel cell as well as 30 percent of the entire cost of the fuel cell [10]. Pins, straight, double serpentine, serpentine, interdigitated channels designs are some of the bipolar plate's configurations that have been investigated in recent years $[11,12]$. The pin type flow channels and that of the interdigitated flow channel were also reviewed [13].

Atul and Ramana [14] and Tabbi et al [15] observed that one of the main challenges hindering the ability of a fuel cell to operate at its full potential is the flow channel design and this in turn 
impact the commercial viability of the use and wide adoption of fuel cell worldwide. Gas distribution evenly through the flow channels leads to $50 \%$ increase in the power density according to an investigation carried out by Carton et al [6]. The by-product of the electrochemical reaction in the fuel cell is often water and heat. In effect, dissipation of the byproduct out of the fuel cell will critically contribute to the performance of the fuel cell by reducing the chances of flooding in the membrane. This phenomenon is likely to occur because of portions of the membrane covered by water hence not contributing to the electrochemical reaction. Sometimes the water is also collected in the Gas diffusion layer as well. The area on the membrane that does not participate in the chemical reaction is referred to as a dead zone. Drying of the membrane could also have a detrimental effect on the fuel cell as protonic conductivity through the membrane would be reduced due to an increase in resistance in the membrane hence leading to high ohmic losses. Another investigation carried out concluded that the power output for interdigitated designs was 1.4 times higher compared to traditional bipolar plate designs (Serpentine). They further argued that reducing the cross-sectional area of the flow channel from $50.75 \%$ to $66.67 \%$ of traditional flow field designs will increase the performance of the fuel cell appreciably [16]. Nguyen [17] also explored the impact of varying physical conditions such as temperature, atmospheric pressure, humidity and stoichiometric ratio on the performance of the fuel cell. The report also confirmed that the fuel cell can perform better even at higher temperature provided the humidification temperature is increased as was also reported by Tabbi et al. [2]. Another conclusion made was that when the fuel cell is being operated at a higher current density, the effect of humidifying the reactant at both the anode and cathode region would not influence the performance of the fuel cell in any way. Kazim et al [18] also investigated the effect of the bipolar plate design on water management. The research considered comparing 2 types of landing to channel ratio (1:1 and 2:2) with respect to two different bipolar plate designs i.e. serpentine and interdigitated for two different areas $\left(25 \mathrm{~cm}^{2}\right.$ and $\left.70 \mathrm{~cm}^{2}\right)$. A conclusion was deduced that increasing the cross- sectional area of the channel of the fuel cell reduced the power density. Manso et al [19] considered three dimensional numerical model studies of the counter flow via the GDL for serpentine bipolar plate [19]. The pressure drop was lesser for proton exchange membrane fuel cell without counter flow when compared to that of counter flow. The implications of using varying channel dimensions and configurations were investigated using Ansys by Dilip and Trung [20]. The work established the best optimum channel width and channel depth to increase the performance of the fuel cell. Effect of water management on the performance of the fuel cell using serpentine and interdigitated flow channels was reported by Nguyen [17]. The 
investigation exposed the fact that electro - osmotic drag and back diffusion were the main parameters that helped in the formation of water at the cathode region after the electrochemical reaction between the fuel and oxygen when the current density is high. The rate of water production is normally higher than the rate of its removal hence in the inner porous layers the water accumulates. Water flooding occurs when this happens, and the direct effect is a reduced output voltage or current from the fuel cell [21-27].

A 2-dimensional model developed based on Darcy equation for flow in porous media was also investigated by Cano et al [23].

The standard diffusion equation for transport in the GDL and the boundary conditions obtained from the Butler - Volmer equation were used to describe the physical phenomena occurring in the catalyst region of the PEMFC. The interdigitated bipolar plate design again performed better with the results from the mathematical model they derived showing current density three times that obtained from a traditional serpentine proton exchange membrane fuel cell [24]. Khazae and Sabadbanfan [25] reviewed the literature and studied the effect of the different kinds of flow channel designs including serpentine, straight parallel flow field, z parallel flow field, pin or meshed flow field as well as the interdigitated flow field.

Design of experiments techniques were used to investigate three different flow channel designs of fuel cells operating at low temperatures [22]. Carton and Olabi also studied threedimensional flow through an open pore cellular foam material using Fluent CFD with varying humidification conditions [6].

A 3-dimensional numerical analysis on a radial flow patterned PEMFC was conducted by Shimpalee et al [28]. The effect of relative humidity with respect to flow field design of a rectangular PEMFC having cross sectional area of $24.8 \mathrm{~cm}^{2}$ was also investigated by Liu and $\mathrm{Li}$ [29] who studied the effect of flow pattern of the fuel and oxygen on the performance of the fuel cell. The work showed that increasing relative humidity increased the performance of the fuel cell with a serpentine flow plate design. Impact of the size of the bends in the serpentine flow channel has also been investigated [30 - 32]. The numerical study for determining the current density and the effect of dryness of the membrane on the performance of the fuel cell has all been carried out but there is little parametric studies on the effect of flow field designs on the water management and power output [33]. Optimization of the flow channel for the anode and cathode flow regions is recommended to develop better understanding of water management in a fuel cell to prevent the possibility of the membrane flooding and also to ensure 
141 optimal pressure drop through the flow channels. Detailed information about the fluid 142 dynamics for each humidification parameters considered was equally discussed. Many 143 researchers used CFD in analyzing their design concepts [34 - 39].

144 This work investigates the performance of a fuel cell with an active area of $25 \mathrm{~cm}^{2}$ numerically.

145 The work optimizes the said PEM fuel cell performance with respect to water management in 146 the membrane and the overall performance of the fuel cell at different humidification 147 conditions. This will improve the economics of the use of fuel cells by reducing the operational 148 cost of fuel cells at varying operational conditions and ensuring performance at peak levels.

\section{$149 \quad 2.0$ Model Validation}

150 The computational results generated in Ansys Fluent (shown in appendix A) were first 151 compared with experimental results obtained from the experimental setup shown in Appendix 152 B and those obtained by Cheng et al.[40]. There is a perfect agreement between the numerical 153 results generated in Ansys and those obtained in the laboratory as well as the results of Cheng 154 et al. [40] as shown in Fig. 1. The differences between the current densities of the three results 155 being compared are small and the standard deviation is less than $0.0075 \mathrm{~A} / \mathrm{cm}^{2}$ which is smaller 156 than those obtained by Giri and Bannerjee (1975) [41]. 
Verification of current density of PEM fuel cell

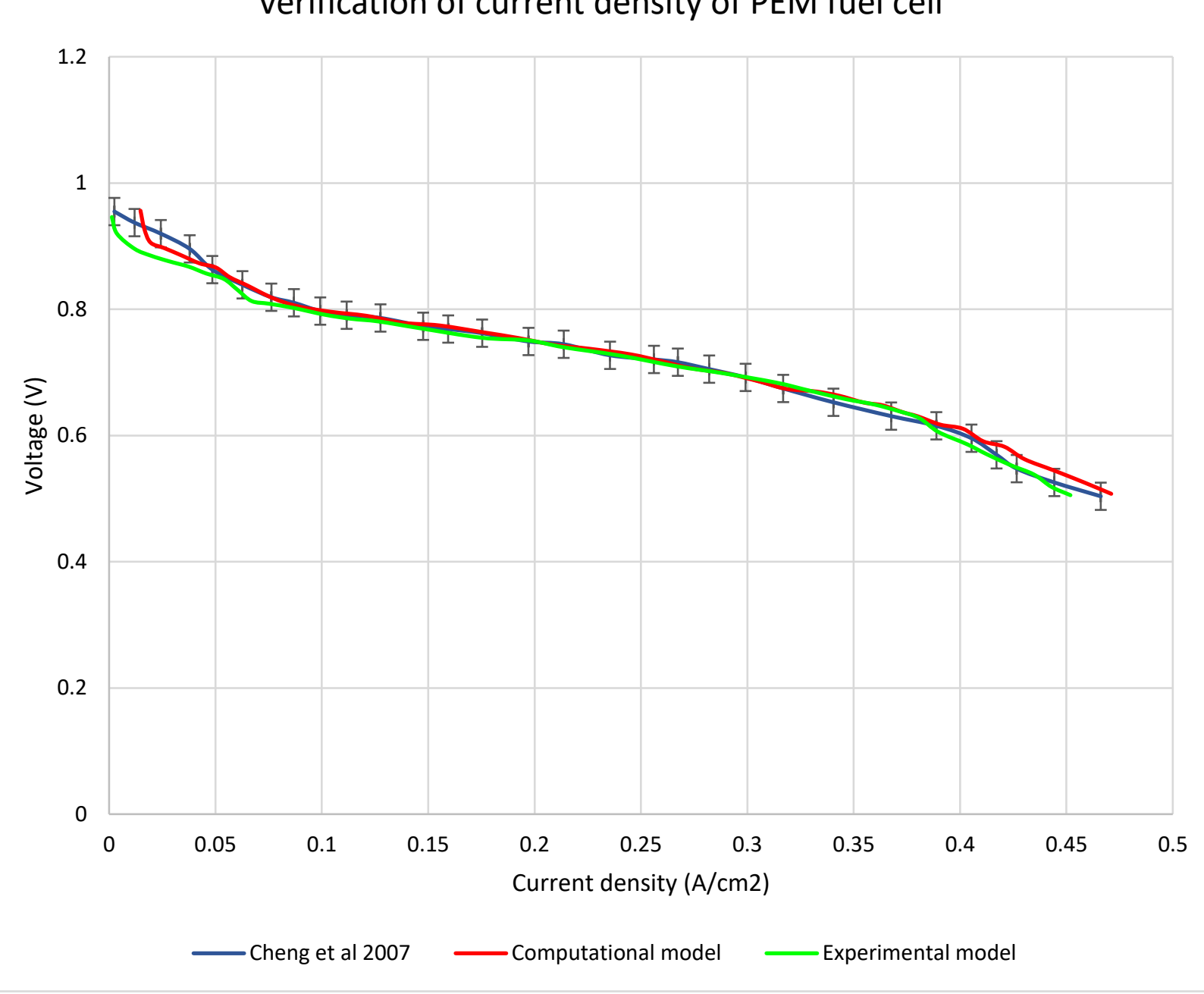

Fig. 1. Numerical verification of the current density of the PEM fuel cell

159 The same observation can be said of Fig. 2, where the differences between power density 160 curves for the three results were also small. Table 1 shows the specific voltage and current

161 density obtained as well as the deviation between the experimental and computational results.

162 The experimental results obtained showed lower values than the numerical/computational 163 results as this can be attributed to experimental physical operating parameters like the cell operating temperature that kept fluctuating in the laboratory. 
Verification of Power density of PEM fuel cell

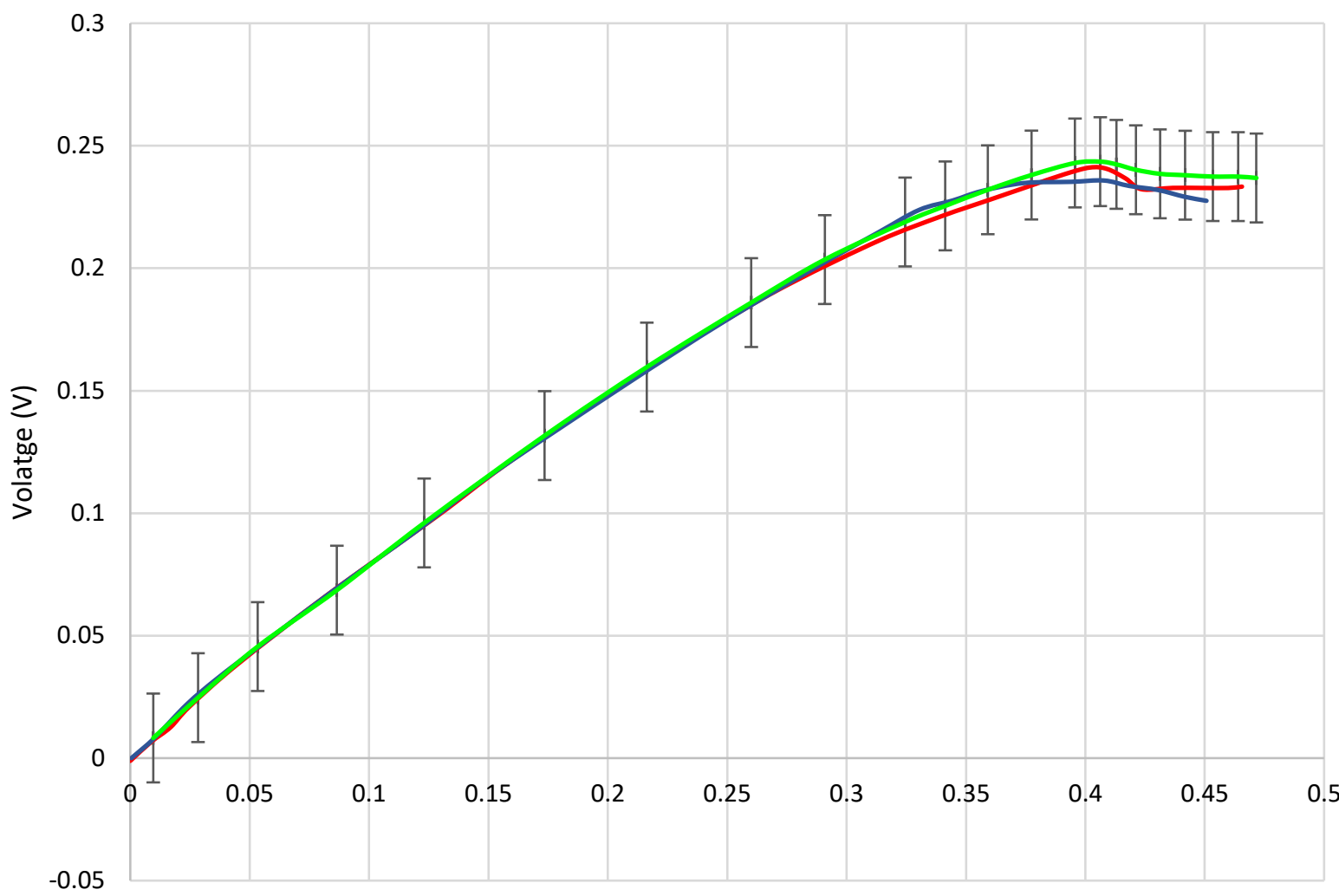

Current density $(\mathrm{A} / \mathrm{cm} 2)$

computational model

—Cheng et al 2007

Experimental model

Fig. 2: Numerical verification of the Power density of the PEM fuel cell

167

Table 1: Comparison between computational and experimental data

\begin{tabular}{|c|c|c|c|c|}
\hline No. & Voltage (V) & \multicolumn{3}{|c|}{ Current density $\left(\mathrm{A} / \mathrm{cm}^{2}\right)$} \\
\hline & & $\begin{array}{c}\text { Experimental } \\
\text { results }\end{array}$ & Computational & Percentage \\
\hline & & 0.0010 & 0.0015 & 0.66 \\
\hline $\mathrm{a}$ & 0.90 & 0.05528 & 0.05429 & 1.80 \\
\hline $\mathrm{b}$ & 0.85 & 0.08551 & 0.09001 & 4.99 \\
\hline $\mathrm{c}$ & 0.80 & 0.1941 & 0.18510 & 4.60 \\
\hline $\mathrm{d}$ & 0.75 & 0.2755 & 0.2801 & 1.64 \\
\hline $\mathrm{e}$ & 0.70 & 0.3489 & 0.3378 & 3.18 \\
\hline $\mathrm{f}$ & 0.65 & & & \\
\hline
\end{tabular}


2.1 Effect of the direction of the flow of the gas.

171 The first numerical simulation that was done was to determine the pattern of the flow of the 172 gas as this will have a large impact on the performance of the fuel cell. Two types of flow 173 patterns were considered, namely, parallel and counter flow patterns. Each of these flow 174 patterns were considered for one specific geometry as shown in Fig. 3.

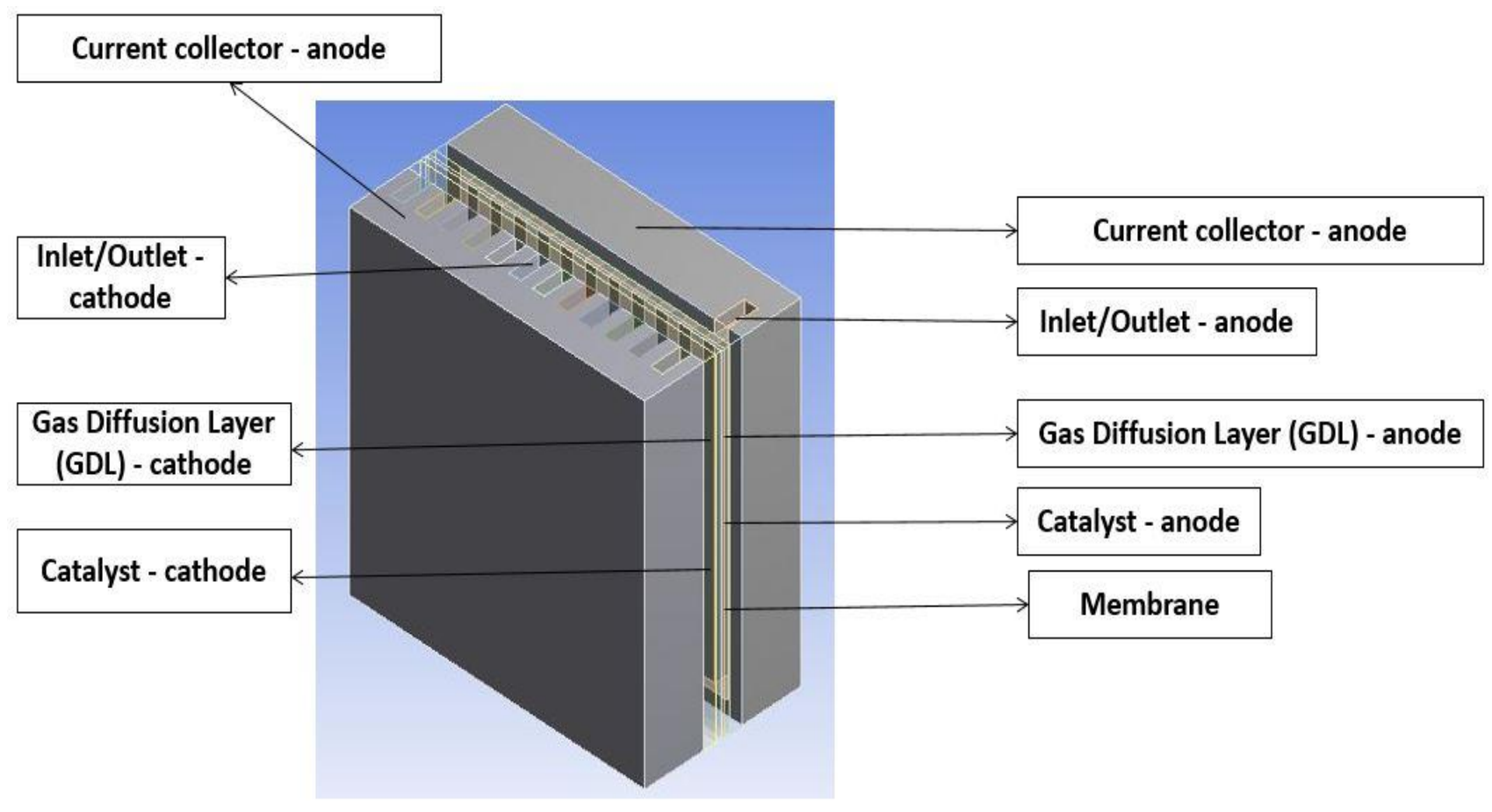
Fig. 3: PEM fuel cell geometry used in the simulation. 
a.

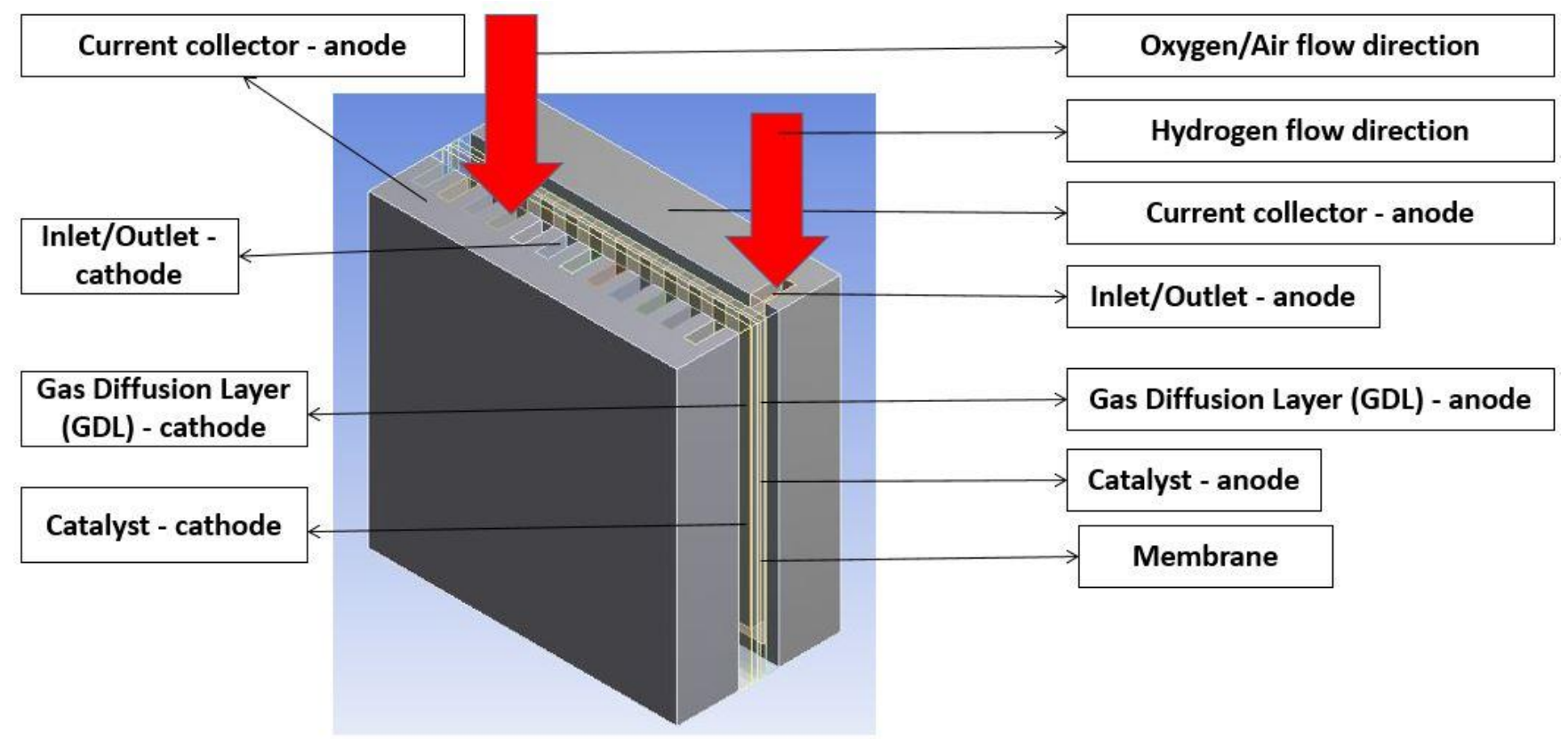

b.

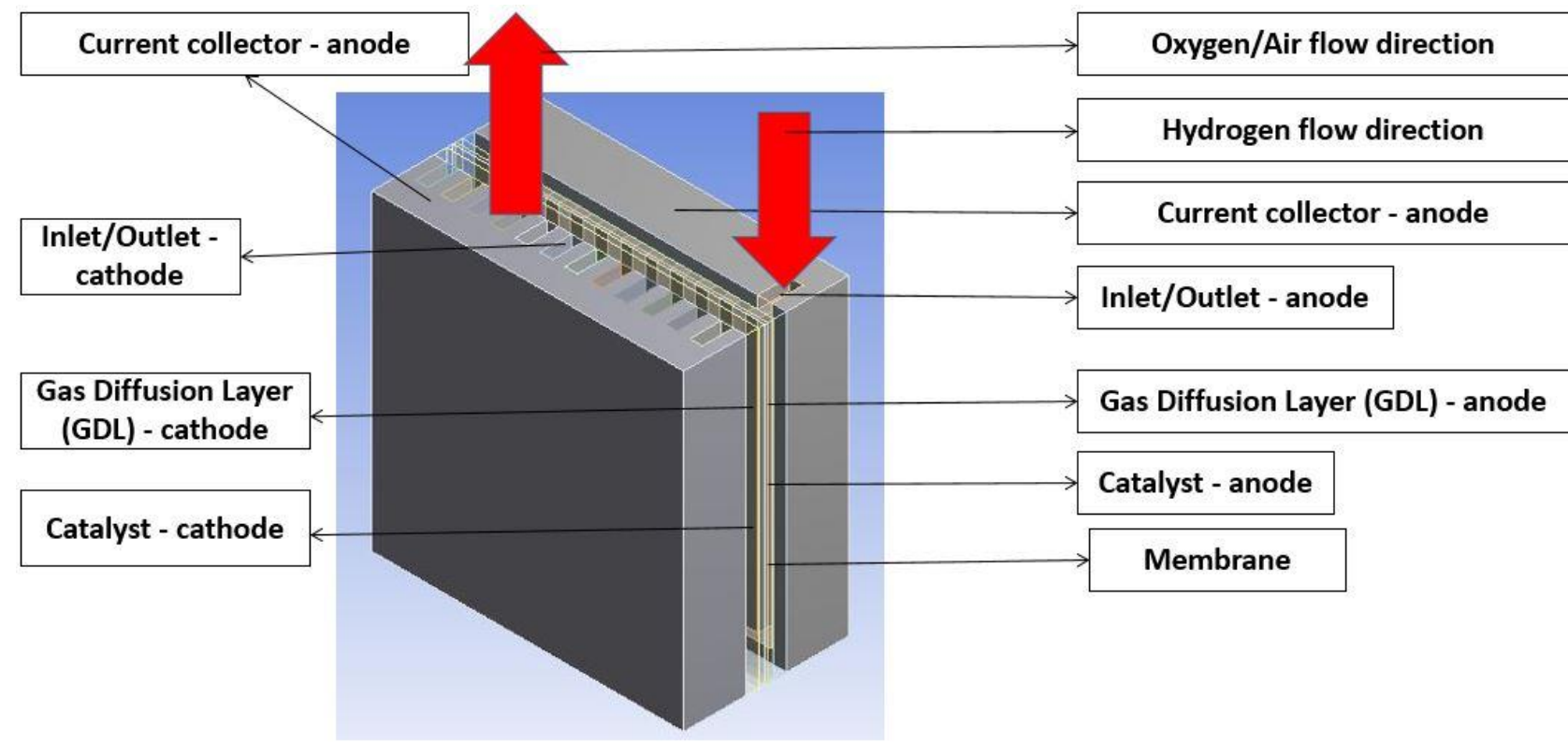

Fig. 4: Flow directions in the PEM fuel cell module a) Parallel flow b) Counter flow. 
The counter/cross flow pattern (Fig. 4b) results in the gases moving in opposite direction to each other and in the parallel flow (Fig. 4a) arrangement all the gas flows in the same direction. It is also possible to design the flow channel for both the hydrogen and oxygen to flow in different (mixed) direction.

\subsubsection{Parallel flow pattern}

\section{Concentration of hydrogen}

This flow direction as shown in Fig. 4a allows the gas to be evenly distributed at the anode region of the fuel cell while at the cathode region the oxygen gas is also evenly distributed. It must be noted that a good distribution of the gas in the flow channel often leads to more current being generated by the fuel cell. It also supports the life span of the fuel cell as it aids in the water management of the cell.

Fig. 5 shows the hydrogen concentration at the anode region. The concentration of the hydrogen gas in Fig. 5 drops gradually between the inlet and the outlet indicating that the hydrogen is consumed as it flows from the inlet to the outlet of the anode flow field.

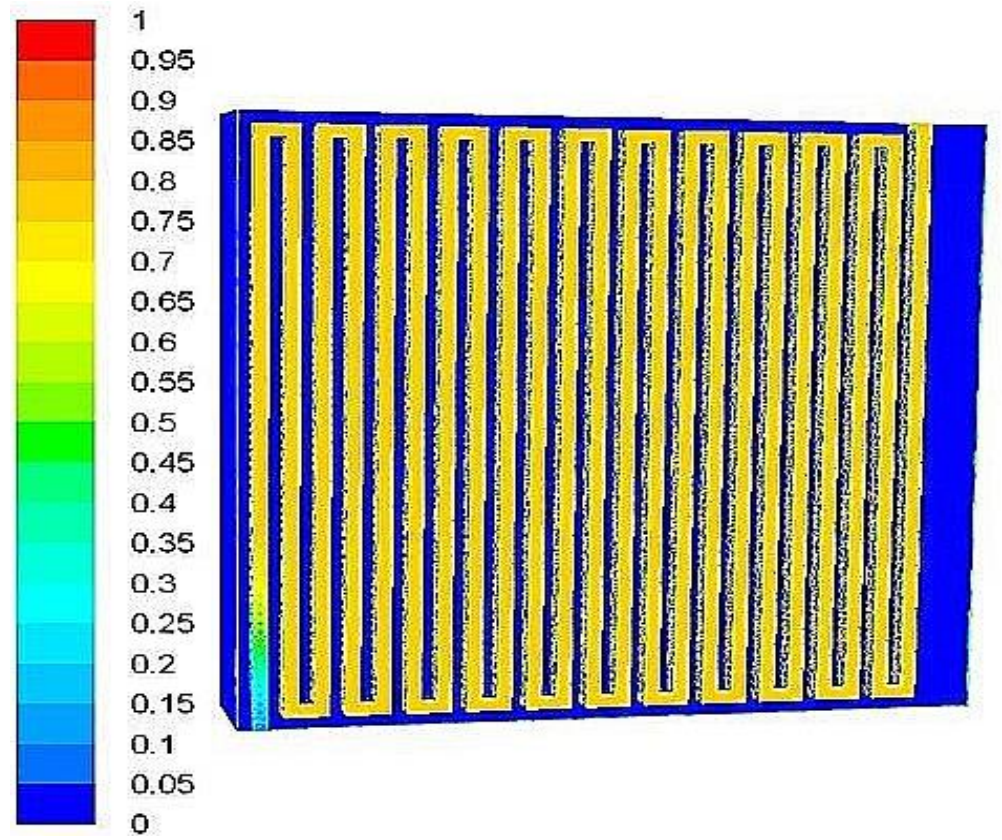

Fig. 5: Hydrogen mass fraction in the anode region of the fuel cell

The flow of the gas from the inlet to the outlet using this approach facilitates easy consumption of the hydrogen gas in the catalyst layer producing the electrons $\left(\mathrm{e}^{-}\right)$and protons $\left(\mathrm{H}^{+}\right)$. 
209 Oxygen gas is introduced to the fuel cell through the cathode region and it often comes either 210 as pure oxygen or air. The drop in concentration of the oxygen at between the inlet and outlet 211 indicates the consumption of the oxygen as it passes the cell in this flow channel direction. The 212 ionised oxygen atoms react with the hydrogen ions released from the anode region of the fuel 213 cell to form water which is the by-product of the electrochemical reaction. Fig. 6 shows oxygen 214 mole fraction contour in the cathode region of the fuel cell which has 12 oxygen flow channels.

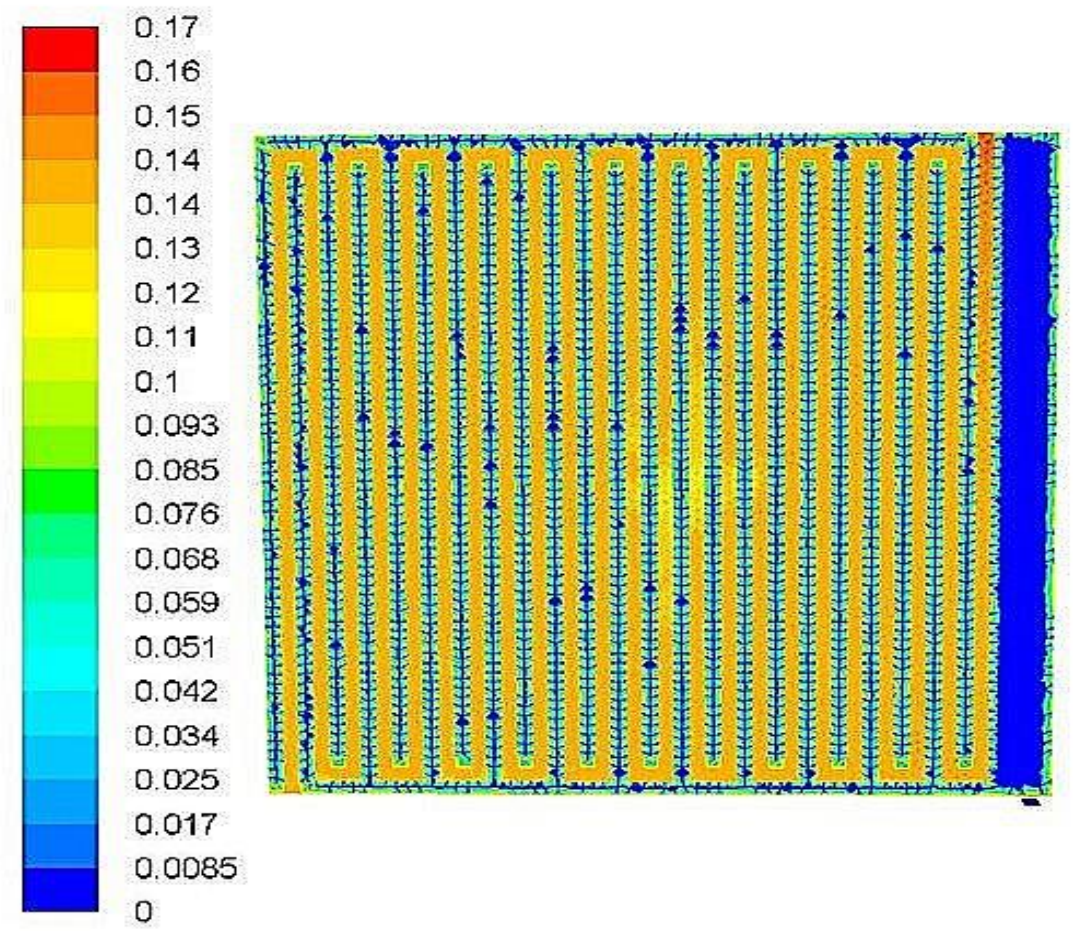

Fig. 6: Oxygen mole fraction contour in the cathode region of the fuel cell

217 Water concentration through the entire flow channel

218 The hydrogen diffuses from the anodic electrode to the cathodic electrode of the PEMFC. The 219 hydrogen ions then react with the oxygen atom at the cathodic electrode leading to the 220 formation of water and the electrons then flow through an external circuit. 


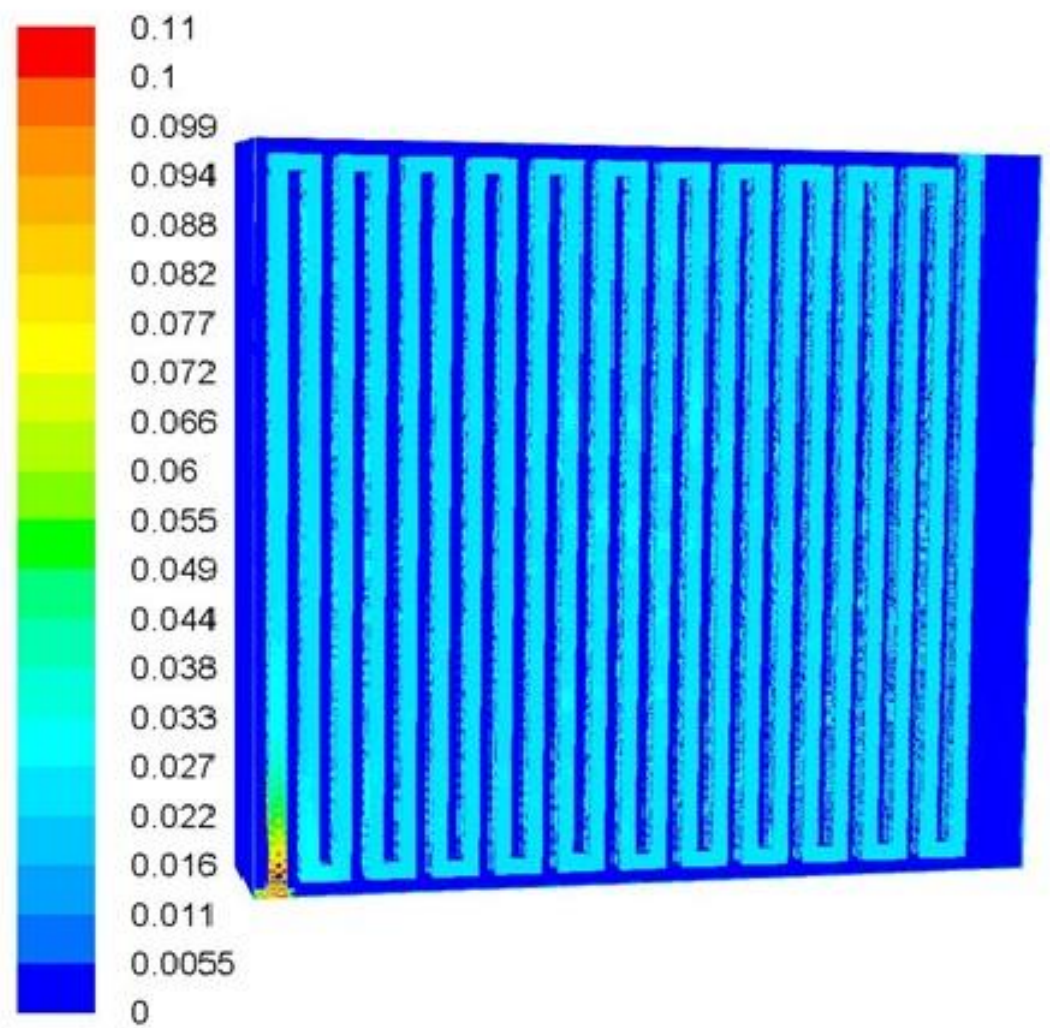

Fig. 7: Water concentration through the anode region of the fuel cell

223 It is observed as shown in Fig. 7 that the largest amount of water will be produced in the mid 224 region because that is where the electrochemical reaction will occur, and the water observed at 225 the anode region is due to the fact that the hydrogen gas is $20 \%$ humidified. A careful examination of Fig.7 also shows that the water concentration increases from the inlet to the outlet. The outlet water content is lower than the inlet indicating that a good amount of water will be removed from the fuel cell even though the building up of the water often start right from the inlet and increase to the outlet.

Protonic Conductivity

The structure as well as membrane hydration has a huge influence on the performance of PEMFCs as it determines the efficiency of the transport of the protons to the cathode region of the membrane.

234 Fig. 8 shows the protonic conductivity of the protons through the membrane. The protonic 235 conductivity is usually expected to be uniform throughout the membrane indicating the 236 availability of all regions of the membrane for electrochemical reaction to occur which leads to power density and output power increases. 


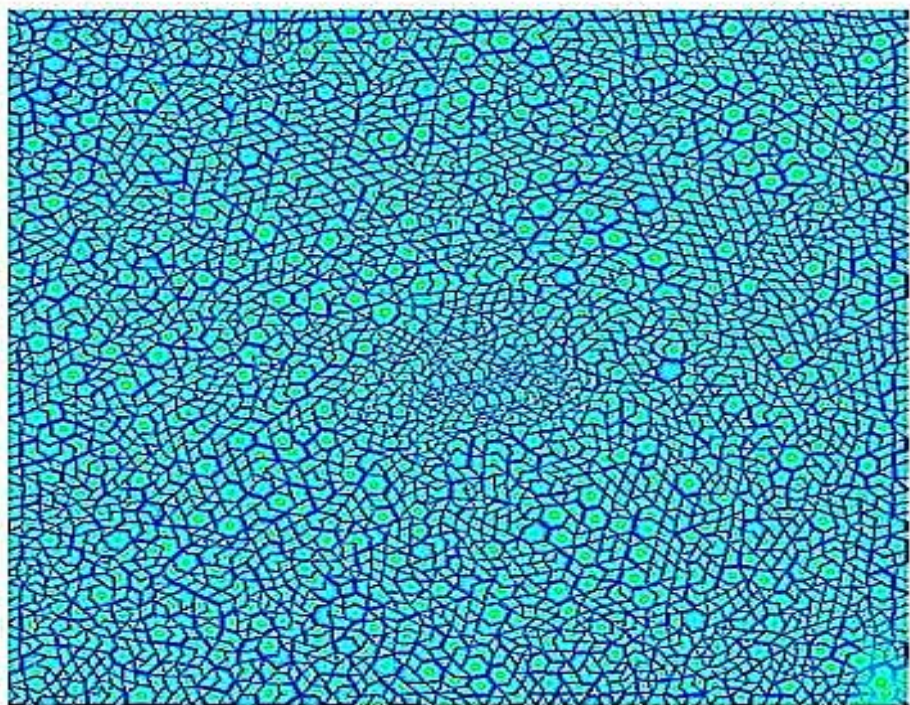

Fig. 8: Contours of protonic conductivity through the membrane of the fuel cell

\subsection{Effect of Counter flow}

241 The cross/counter flow often leads to more current being generated by the fuel cell due to

242 preferential arrangement of the reactive gases moving opposite to each other. As shown on Fig.

$2439 \mathrm{~b}$, the current flux density obtained for the 2 flow directions indicates that more current will

244 be generated if the cross/counter flow arrangement is used. 


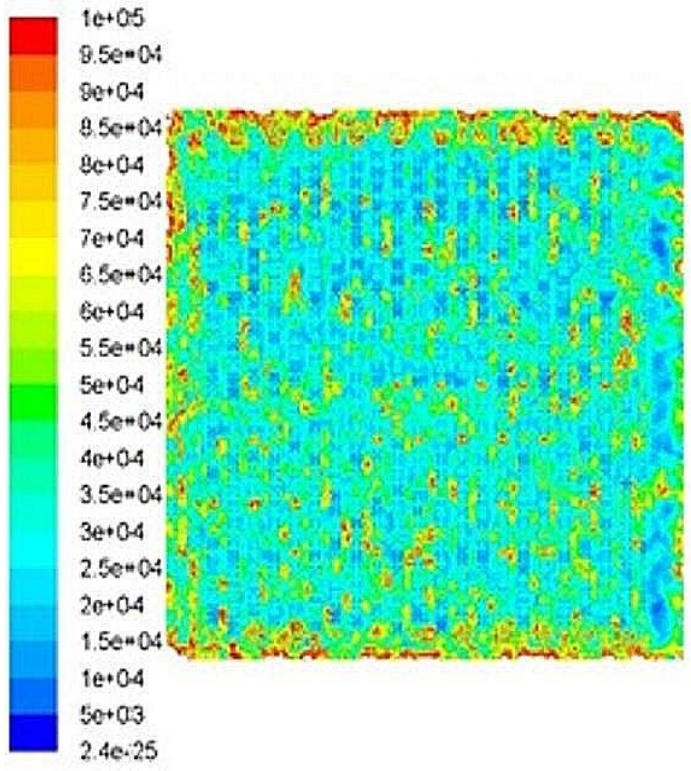

(a)

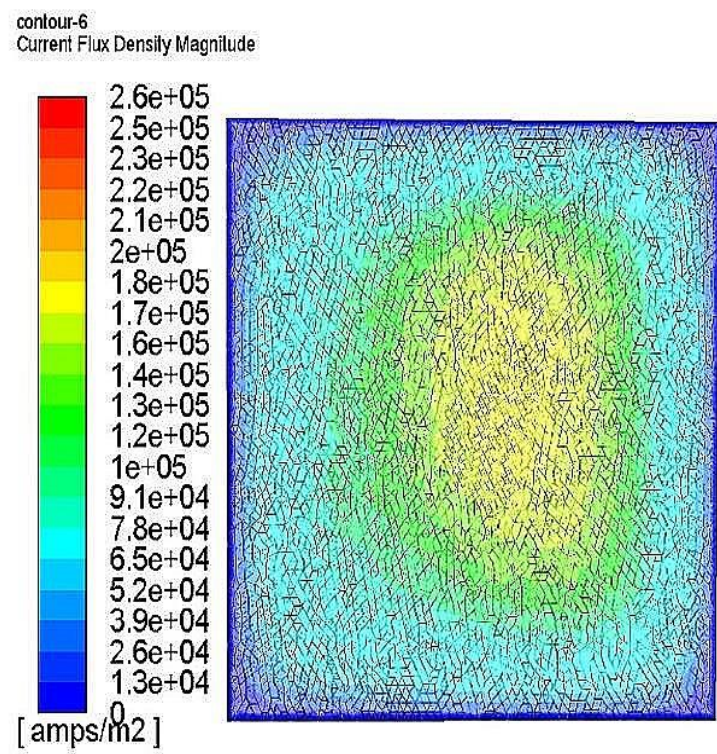

(b)

Fig. 9: Comparison between a) counter and b) parallel flow direction.

247 The polarization curves shown in Fig. 10 and Fig. 11 were used to determine the best flow 248 directions for the rest of the simulations [39]. By analyzing the polarization curves shown 249 below, it becomes clear the counter flow pattern resulted in better performance in terms of 250 power and current density. It showed almost $9.5 \%$ increase in the overall current generated 251 when compared to the parallel flow directions. With the active area of the fuel cell under 252 investigation being $25 \mathrm{~cm}^{2}$, and the cell voltage kept at $0.6 \mathrm{~V}$, the current density obtained using 253 the parallel flow was $0.389 \mathrm{~A} / \mathrm{cm}^{2}$ and the corresponding power density was $0.2334 \mathrm{~W} / \mathrm{cm}$ but the current density for the same constant cell voltage of $0.6 \mathrm{~A} / \mathrm{cm}^{2}$ using a counter flow direction gave the current density and power density as $0.451 \mathrm{~A} / \mathrm{cm}^{2}$ and 0.2706 , respectively, clearly showing the positive impact of the fluid flow pattern on the characteristic performance of PEMFCs. 


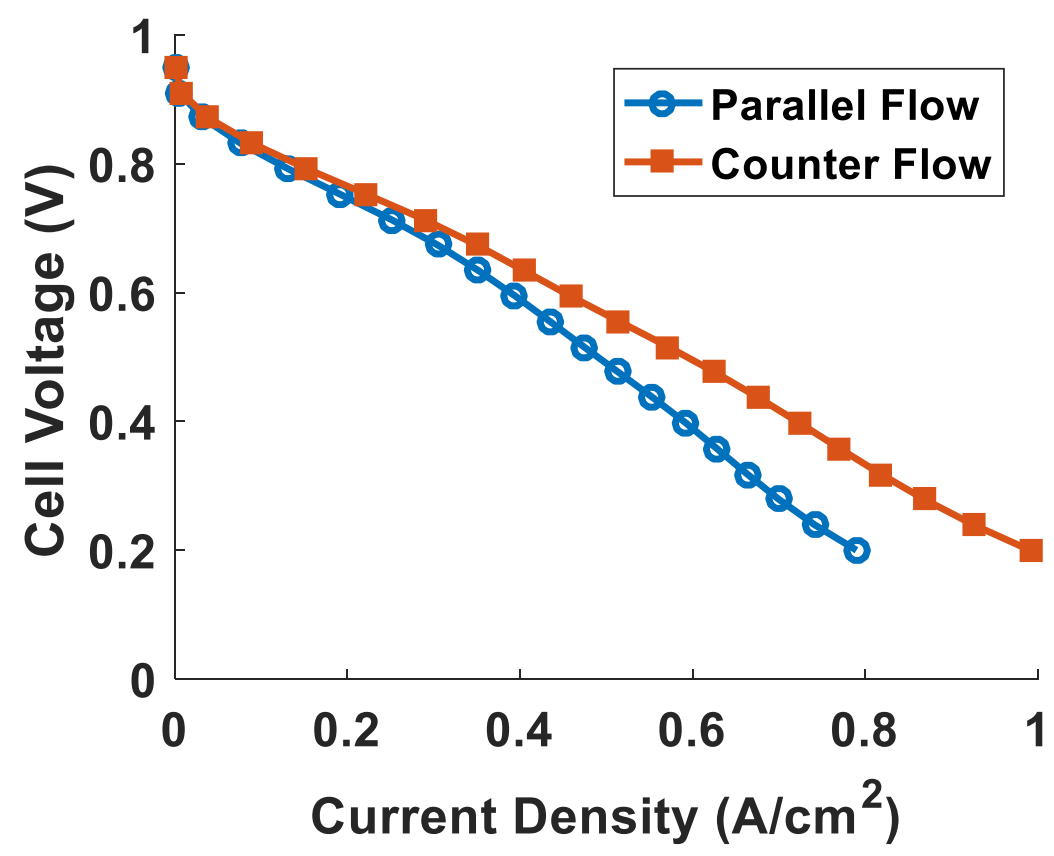

Fig. 10. Polarization curve for the parallel and counter flow direction

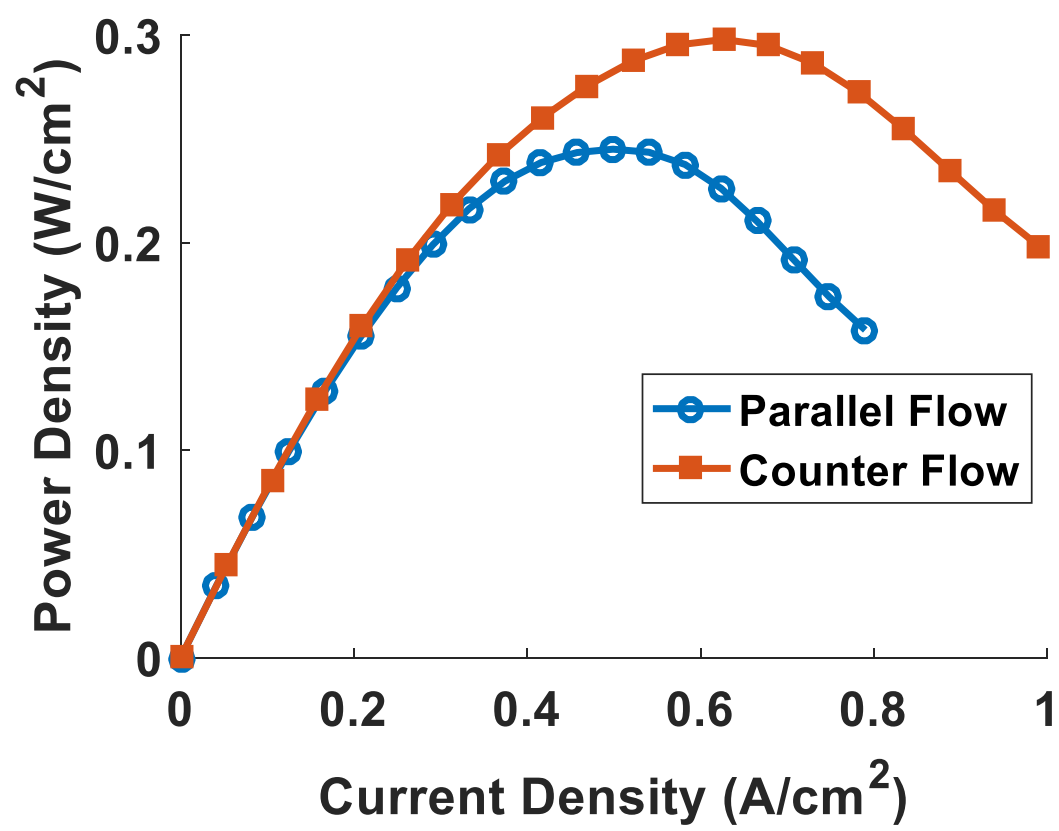

Fig. 11. Polarization curve for counter and parallel flow 


\subsection{Effect of hydrogen gas humidification on the performance of the fuel cell}

267 The by-product of the electrochemical reaction in the fuel cell is water as explained earlier

268 hence it is common for researchers not to humidify the reactive gases to avoid contributing to

269 the flooding of the cell as this will lead to some portions of the active catalyst area become

270 covered with water resulting in reduction of the performance of the fuel cell.

271 The counter flow arrangement was used in the subsequent simulations discussed below. A 272 constant cell voltage of 0.95 was maintained for simulations using dry hydrogen and 273 humidified hydrogen as well as dried oxygen and humidified oxygen. Each of these parameters 274 were varied systematically to determine the impact of each parameter on the overall 275 performance of the fuel cell.
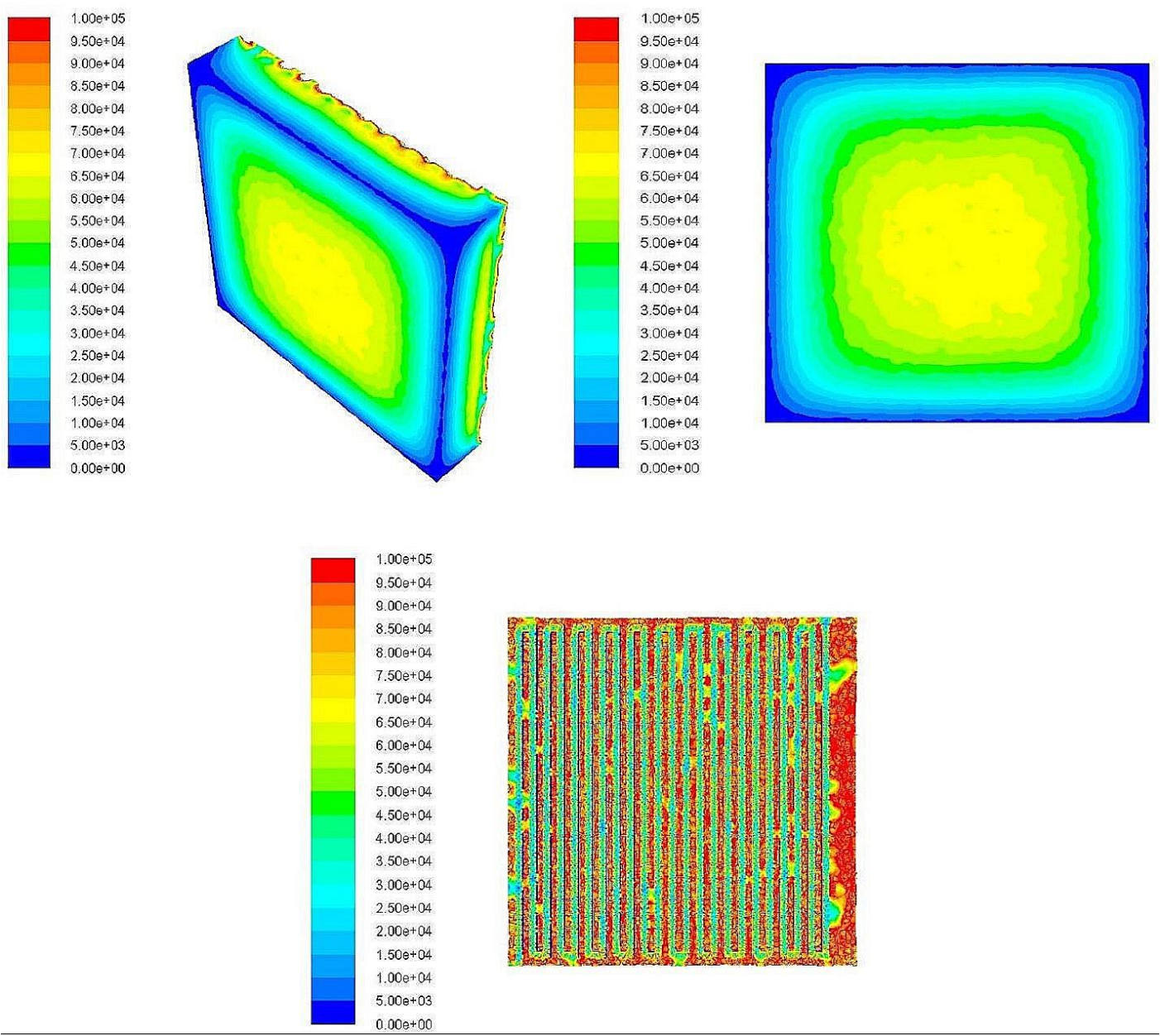

Fig. 12: Current flux density magnitude contours of humidified hydrogen gas through the anode bipolar plate $\left(\operatorname{amps} / \mathrm{m}^{2}\right)$ 
Fig. 12 shows the current flux density profile for a humidified hydrogen gas through the proton exchange membrane fuel cell.

282 It can also be observed that the fuel cell generates more current if the anode reactive gas is 283 humidified as compared to using a dry hydrogen gas as shown in Fig 13. The main rational for 284 the occurrence of this phenomenon is because the membrane close to the anode becomes dehydrated when dry hydrogen gas is used as compared to the use of wet or humidified hydrogen gas. The dehydration increases the resistance in the cell (electrolyte) reducing the release of electrons through the externally connected circuit.

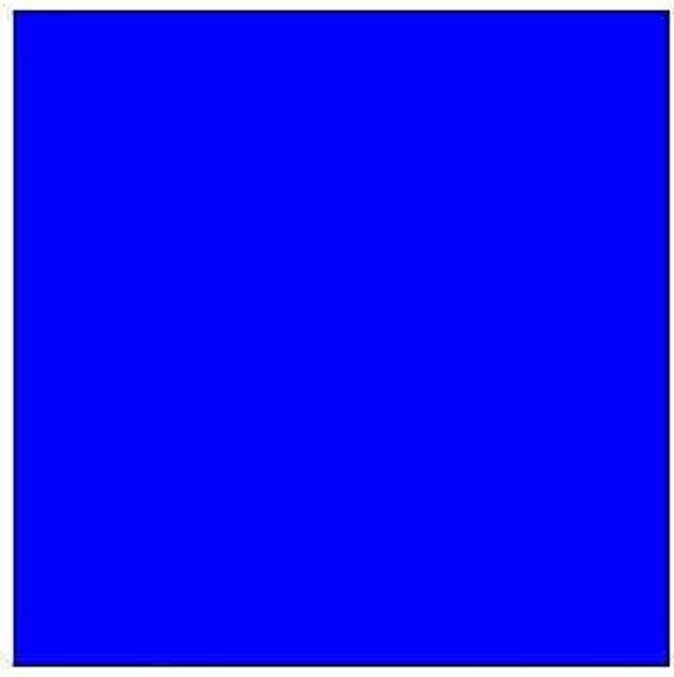

Fig. 13: Current flux density magnitude for dry hydrogen gas $\left(\mathrm{amps} / \mathrm{m}^{2}\right)$

Fig. 14 also shows the mass fraction contour for both the humidified hydrogen and dry hydrogen. As expected due to the hydrogen gas being humidified in Fig. 14a, some of the area is occupied by the hydrant (water) throughout the entire flow channel compared to the dry hydrogen where the space above the membrane is predominantly hydrogen. Also in the latter case, more hydrogen gas will flow through each channel arm compared to the humidified gas, the dearth of water in the gas stream leads to reduced membrane humidification and increased resistance to proton movement with negative impact on the overall performance of the cell. 

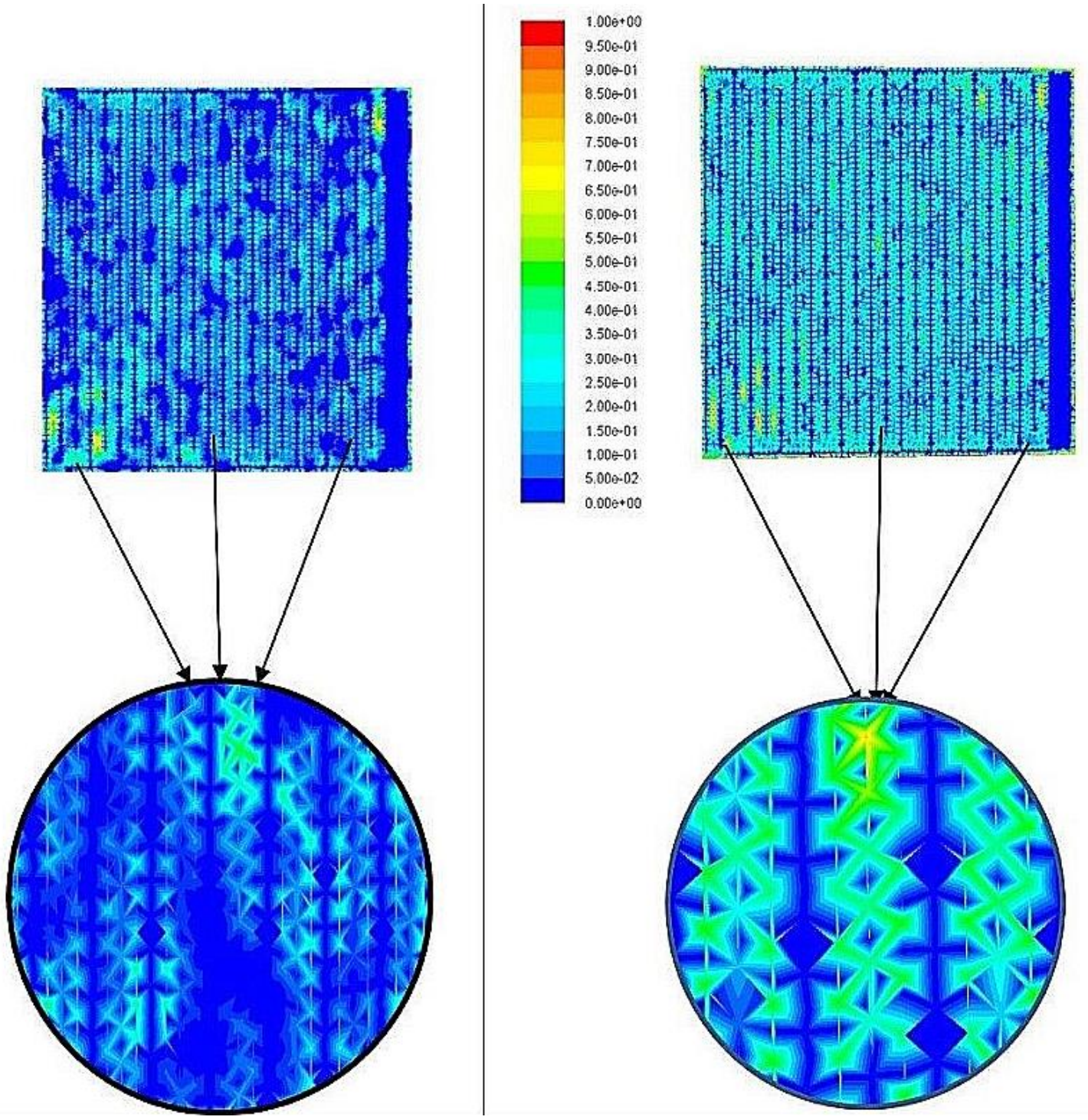

Fig 14: Mass fraction of hydrogen a) humidified b) dry hydrogen

Membrane water concentration

300 A good amount of humidification of the membrane as captured in Fig. 15 is required in order 301 for the protonic conductivity through the membrane to be highly efficient. Using $100 \%$ dry 302 hydrogen gas will make the membrane dry reducing the transport of the hydrogen ions through 303 the membrane. This is one of the important reasons for the performance of PEMFCs being very 304 low when pure dry hydrogen is used. 


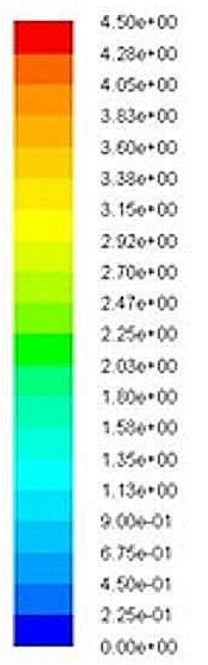

305

306

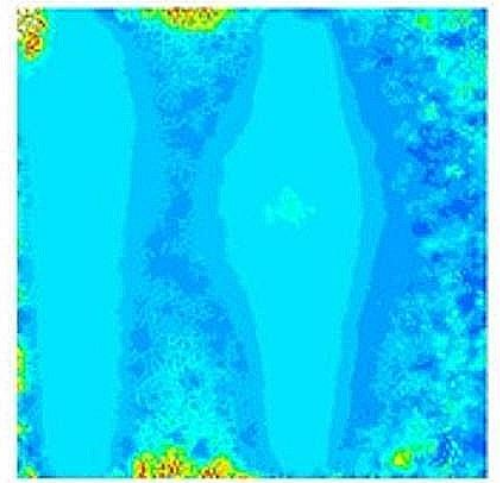

(a)
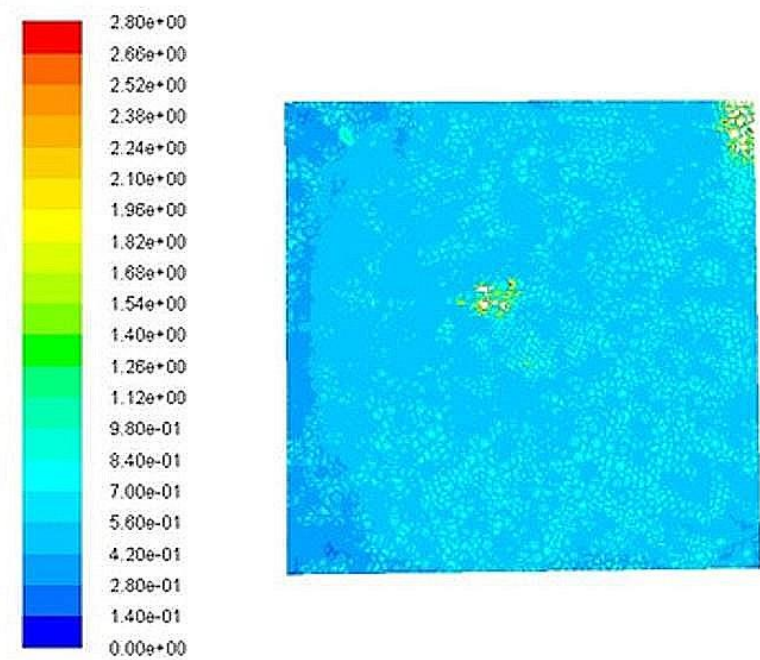

(b)

Fig. 15. Membrane protonic conductivity (V) a) humidified b) dry hydrogen

307 Overpotential

308 The overpotential through the fuel cell for both humidified and dry hydrogen gas was also

309 studied and from Fig. 16. It can be seen that the loss due to using dry hydrogen is higher when compared to using a humidified hydrogen gas.

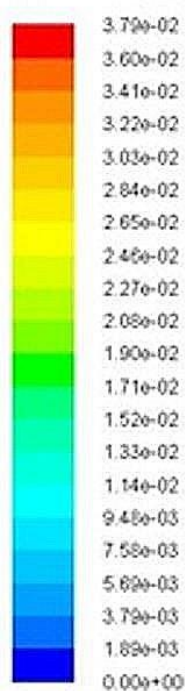

311

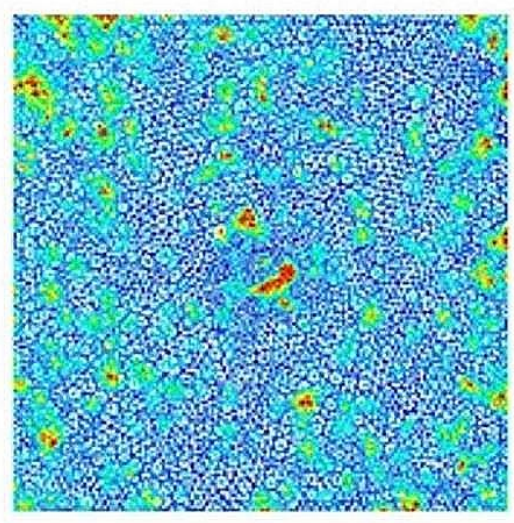

a)

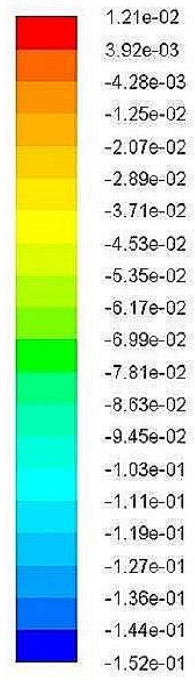

b)

Fig. 16: Membrane over potential (v) for dry and humidified hydrogen gas.

313 The polarization curves of Fig. 17 show that the limiting current density when using a 314 humidified hydrogen gas occurs slower than when using a dry hydrogen gas. This occurs 
because the losses when a dry gas is used are always greater than when using a humidified hydrogen gas. A fuel cell cannot produce any current greater than its limiting current value hence using the dry hydrogen gas yields small amount of current from the fuel cell.

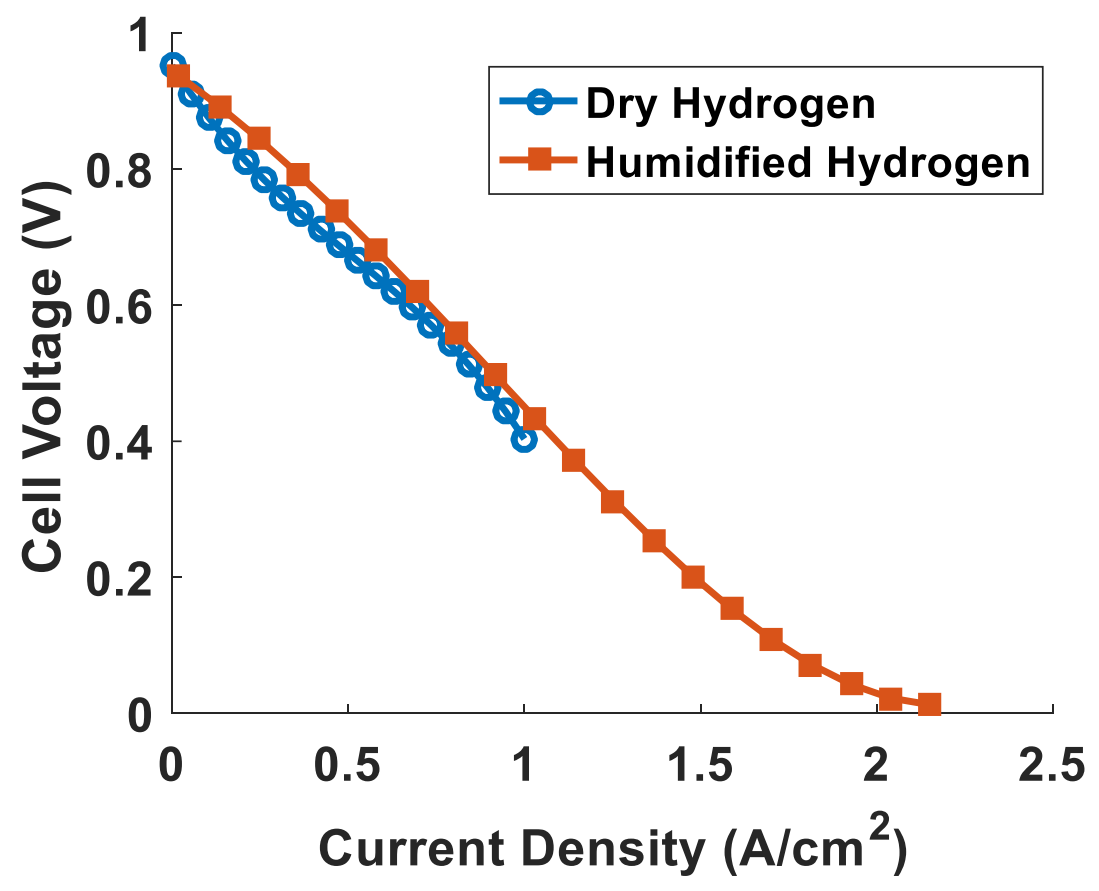

Fig. 17: Comparison of the effect of using dry hydrogen and humidified hydrogen gas hydrogen gas performs better than the dry gas.

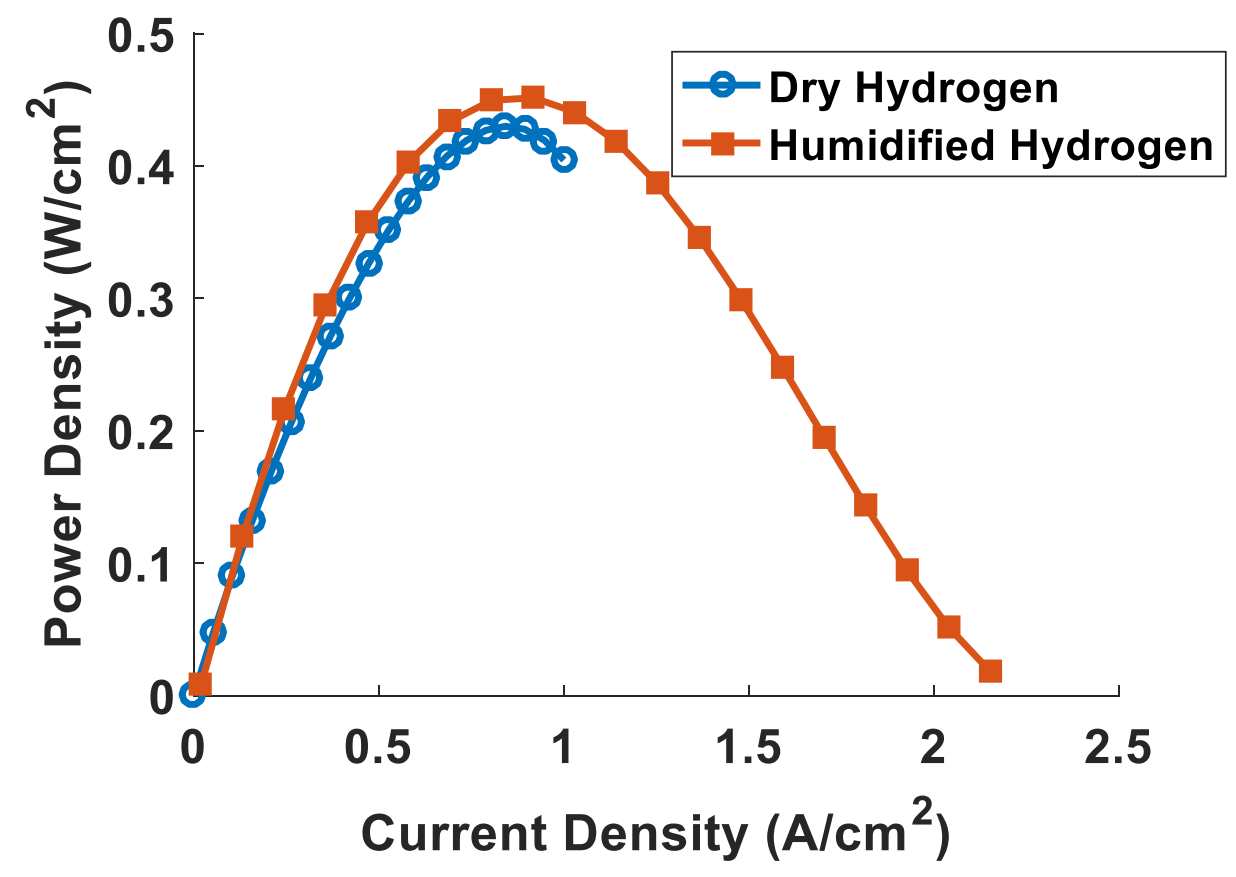




\subsection{Effect of humidification of the oxygen gas at the cathode region.}

325 Since the need for the hydrogen to be humidified is confirmed, the investigation progressed to 326 determine the effect of oxygen humidification or air humidification on the performance of a 327 fuel cell and which of the two will be the better option to improve the characteristics performance of any PEMFC. The major challenge that determines the performance of most fuel cells in general is how the by-product which is water can be removed effectively out of the fuel cell while keeping the membrane kept properly humidified.

The overpotentials are affected by the water content in the fuel cell and dehydration or too much water in the fuel cell can all have adverse effects on the overall performance of the fuel cell. For good protonic conductivity, the membrane is recommended to be properly humidified. Protonic conductivity reduces in instances where the membrane is not well humidified thus increasing the cell resistance and activation overpotentials therefore increases due to the membrane drying out. Too much water will also impede the reactant transport to the active catalyst layer for electrochemical reaction to occur and this situation increases the diffusion overpotential. One proactive way of maintaining the membrane constantly hydrated is through the humidification of the oxygen gas as well. The humidification of the oxygen gas is also dependent on the gas temperature, pressure, channel design and the thickness of the membrane. The current density generated usually defines the amount of water produced by the fuel cell. Fig. 19 shows the water transport process through a fuel cell. 


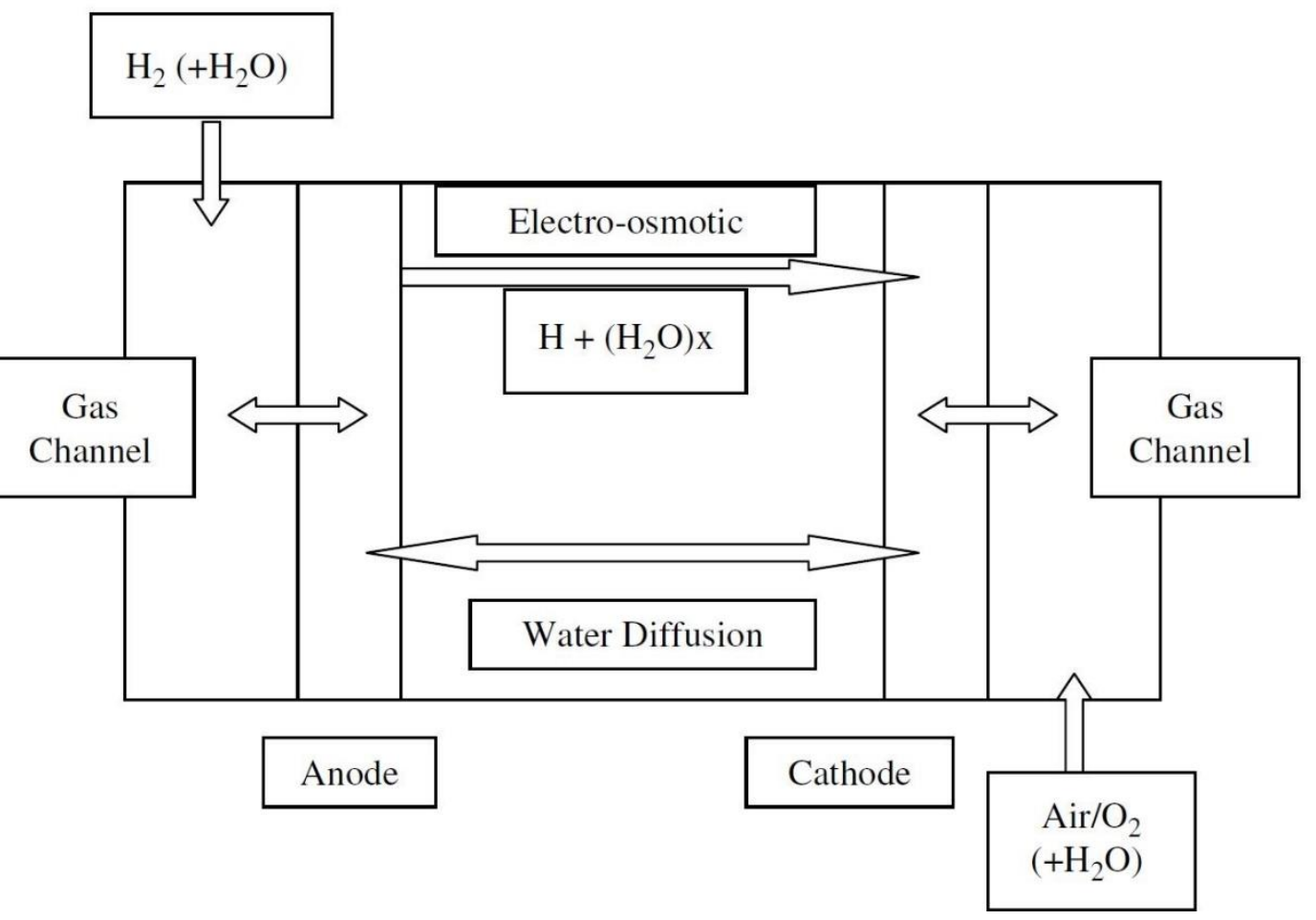

Fig. 19: Transport processes in Fuel cell

345 Whenever a load is placed on the fuel cell electro-osmotic transport process occurs. As the hydrogen ions flow through the polymer from the anode to the cathode, they carry water molecules with them. The number of water molecules that the hydrogen ions carry along on average is called the electro-osmotic drag coefficient.

Water diffusion through the membrane occurs when the concentration gradient in the cathode push the water through the membrane and this process is called the back diffusion. Water accumulation at the cathode region which normally leads to flooding of the fuel cell if not carefully checked is caused by these two processes: electro-osmotic drag and back diffusion. The water formed at the cathode can be removed from the PEMFC through the flow channels. Another method of removing water is by using the reactant gases. Some reactant gases carry the by product (water) along as they flow through the fuel cell especially when they are under saturated or flowing at high rates. The efficiency of water removal also depends on the operating conditions such as temperature, pressure and gas flow rates.

For this investigation, the simulations were carried out using Air with $100 \%$ relative humidity (RH), Air with 50\% RH and dry oxygen and the simulation results were compared with those obtained experimentally. 


\subsection{Performance of a fuel cell with $100 \%$ RH of Air}

363 As with the increase in the humidity of the hydrogen gas, 100\% RH of air showed a better fuel cell performance as shown in Fig. 20 when compared with dry and lower RH values. This is because the humidified air did not strip the membrane of water and prevented it from becoming dry thus help protonic conductivity and also increased electro osmotic drag and back diffusion. These factors helped keep the fuel cell operating at its maximum potential.

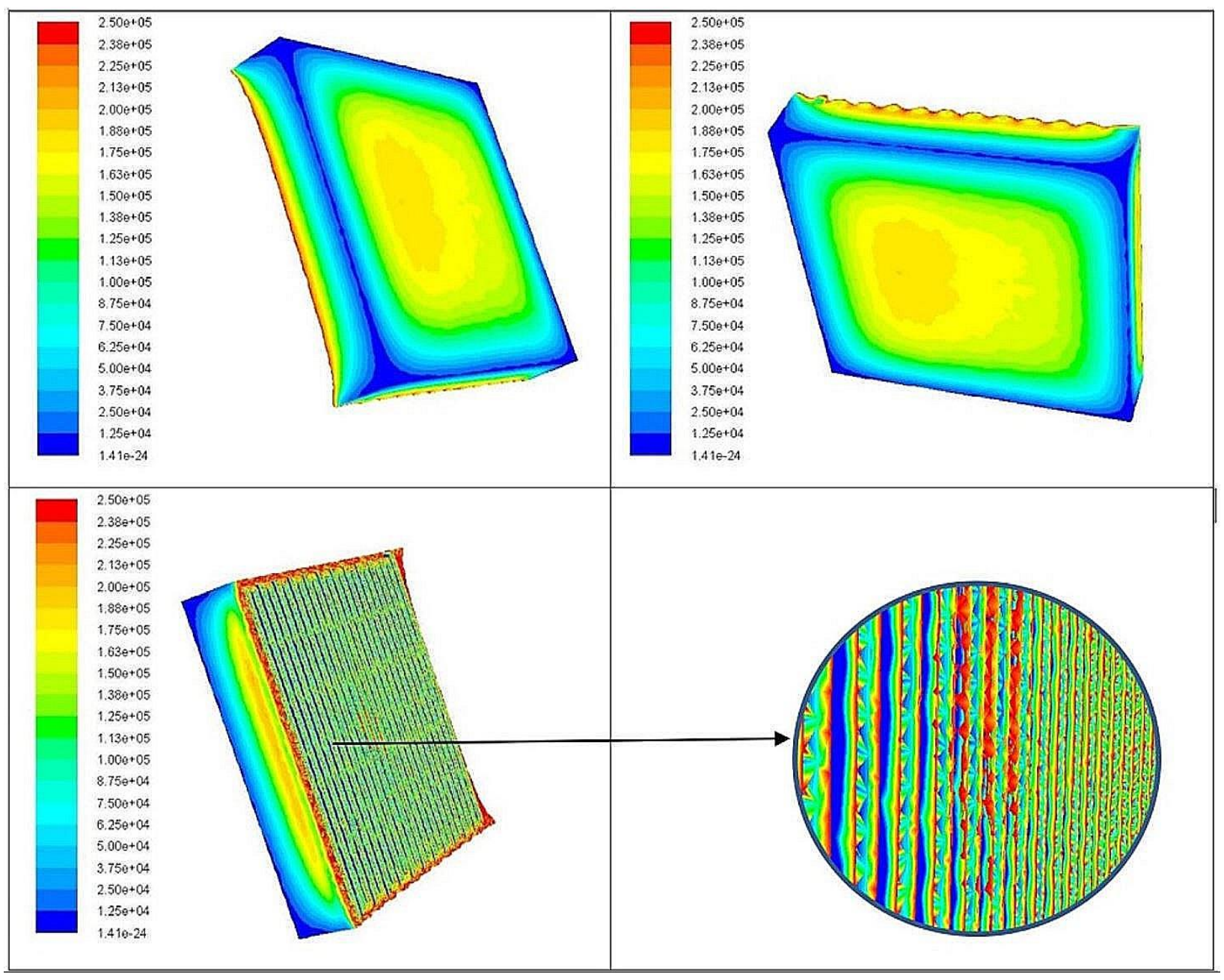

Fig. 20. Current flux density magnitude on the current collector with 100\% RH of Air

Fig 21 shows the water contours in the membrane which indicate that the membrane contains good amount of water which will facilitate the transport of the protons increasing the

372 performance of the fuel cell. As the by-product of the electrochemical reaction is water, the 373 operating cell temperature must be kept high to aid in the easy removal of the product water through vaporization to reduce the risk of flooding. 


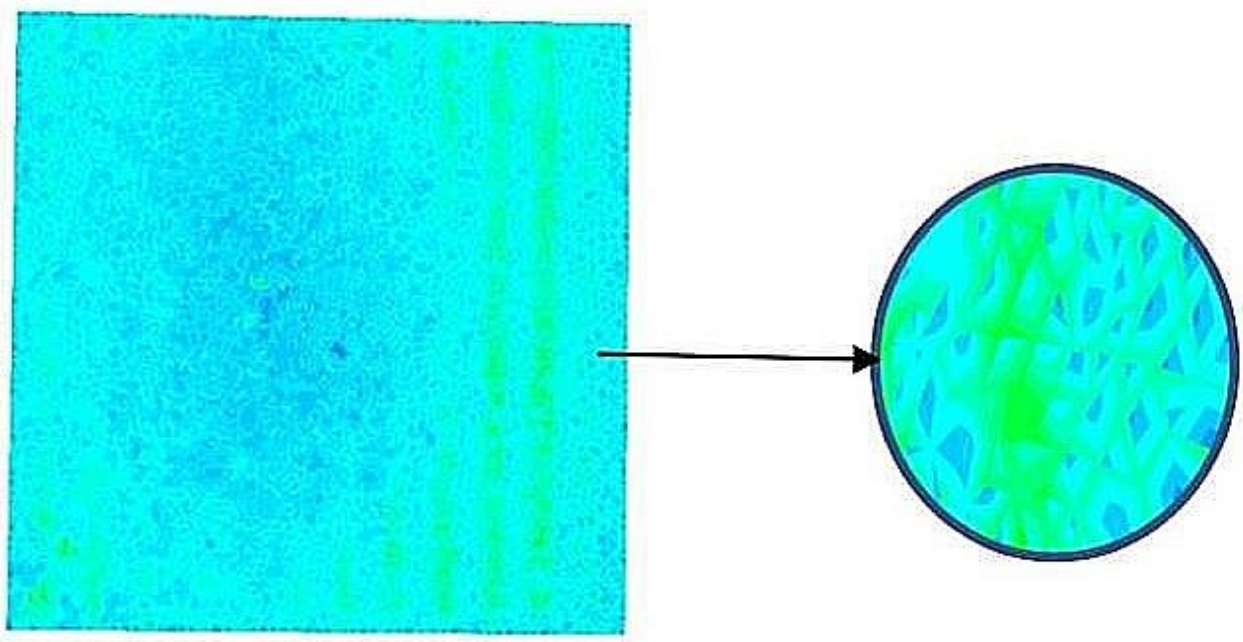

\section{$377 \quad 2.6$ Performance of a fuel cell with $50 \% \mathrm{RH}$ of Air}

378 The performance of the fuel cell with 50\% RH Air is slightly lower than that with 100\% RH 379 Air as shown in Fig. 22 and the fuel cell can still give good amount of current even with 50\% RH 380 Air. As before, the cell operating temperature and the flow rate of the gas should be kept at optimum conditions to reduce the possibility of the fuel cell drying out. 


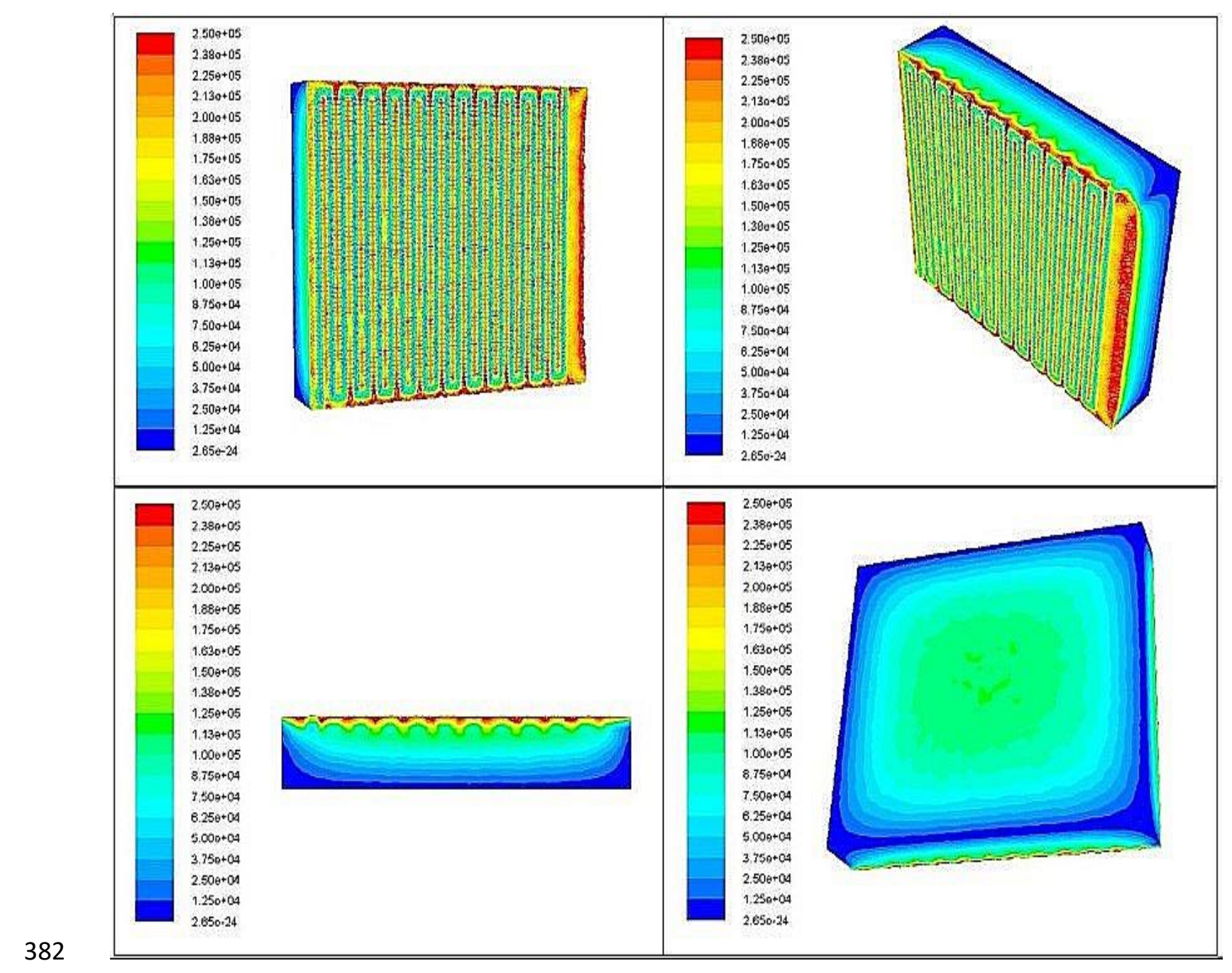

Fig. 22: Current flux density magnitude of the fuel cell at 50\% RH of air

384 Since the relative humidity of the air is only 50\%, the membrane loses water to the air resulting

385 in lower water contents in the membrane (Fig. 22) with corresponding reduction in the protonic

386 conductivity of the membrane. This in turn reduces the flow of protons implying lower current

387 density fluxes as shown in Fig. 23. This increased resistance contributes to the reduced

388 performance of the fuel cell when compared to the cell using 100\% humidified Air. 


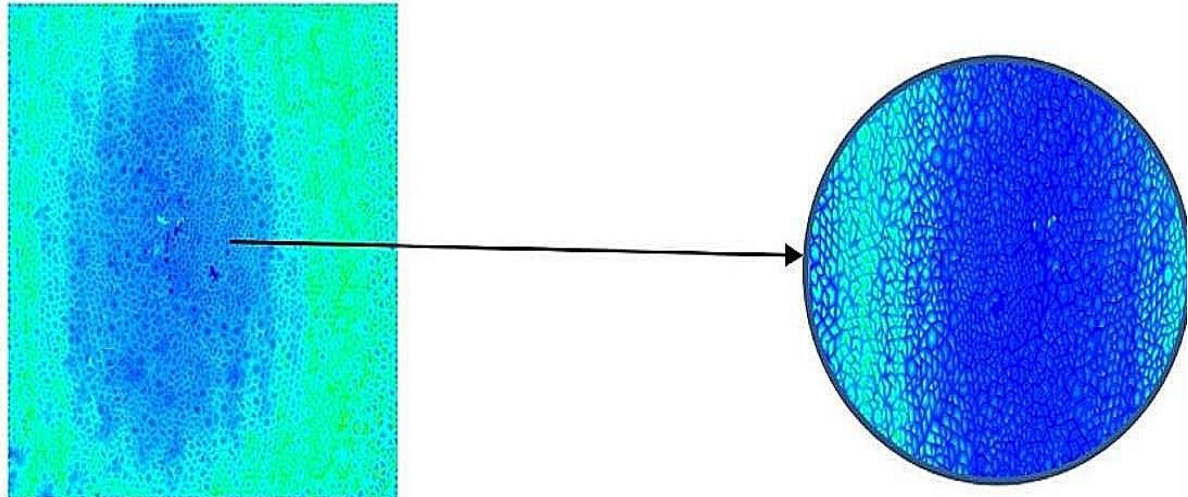

Fig. 23. Membrane water content

\section{$392 \quad 2.7$ Performance of a fuel cell using dry Oxygen}

393 As expected, the use of dry oxygen will have a negative effect on the fuel cell as can be seen 394 from the current flux density magnitude contours obtained from the dry oxygen on the current 395 collectors as shown in Fig. 24 and the amount of current obtained was very low compared with 396 the other simulation results with higher RH. 


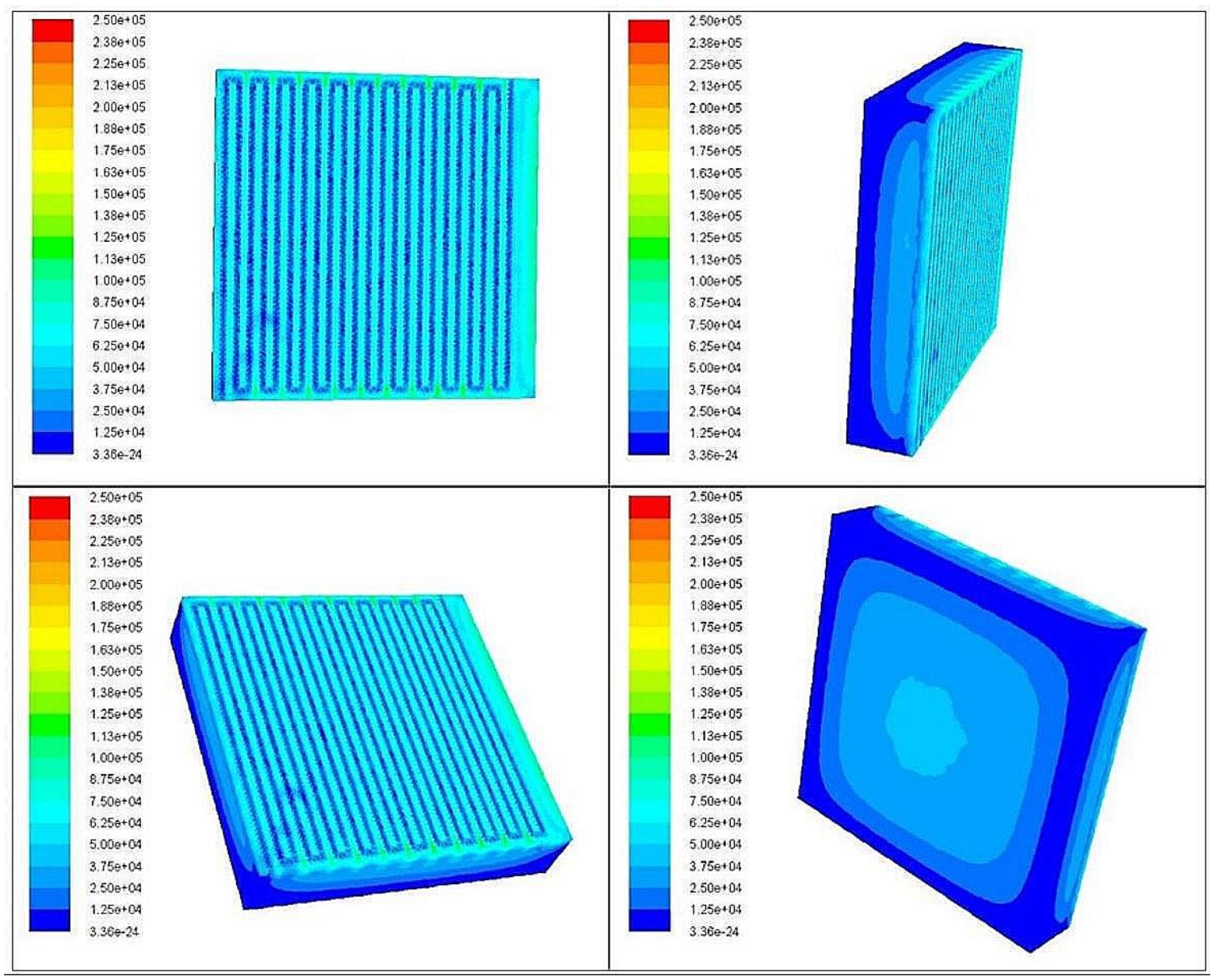

Fig. 24: Current flux magnitude density using dry oxygen

400 An important factor that contributes to the reduction in the performance of PEMFC using dry 401 oxygen is poor back diffusion at the cathode region of the fuel cell due to the membrane being 402 dry when the dried oxygen was introduced to the cell as could be seen in Fig. 25. Even though 403 the electro osmotic drag experienced at the anode region will maintain some amount of 404 moisture in the membrane, the dry oxygen impacts the back-diffusion characteristics of the fuel 405 cell and reduces the performance of the fuel cell in general. With the membrane not being 406 adequately hydrated, the protonic conductivity of the fuel cell will also be reduced as shown in 407 Fig. 26. The low protonic conductivity will also contribute further to the fuel cell not 408 performing properly. 


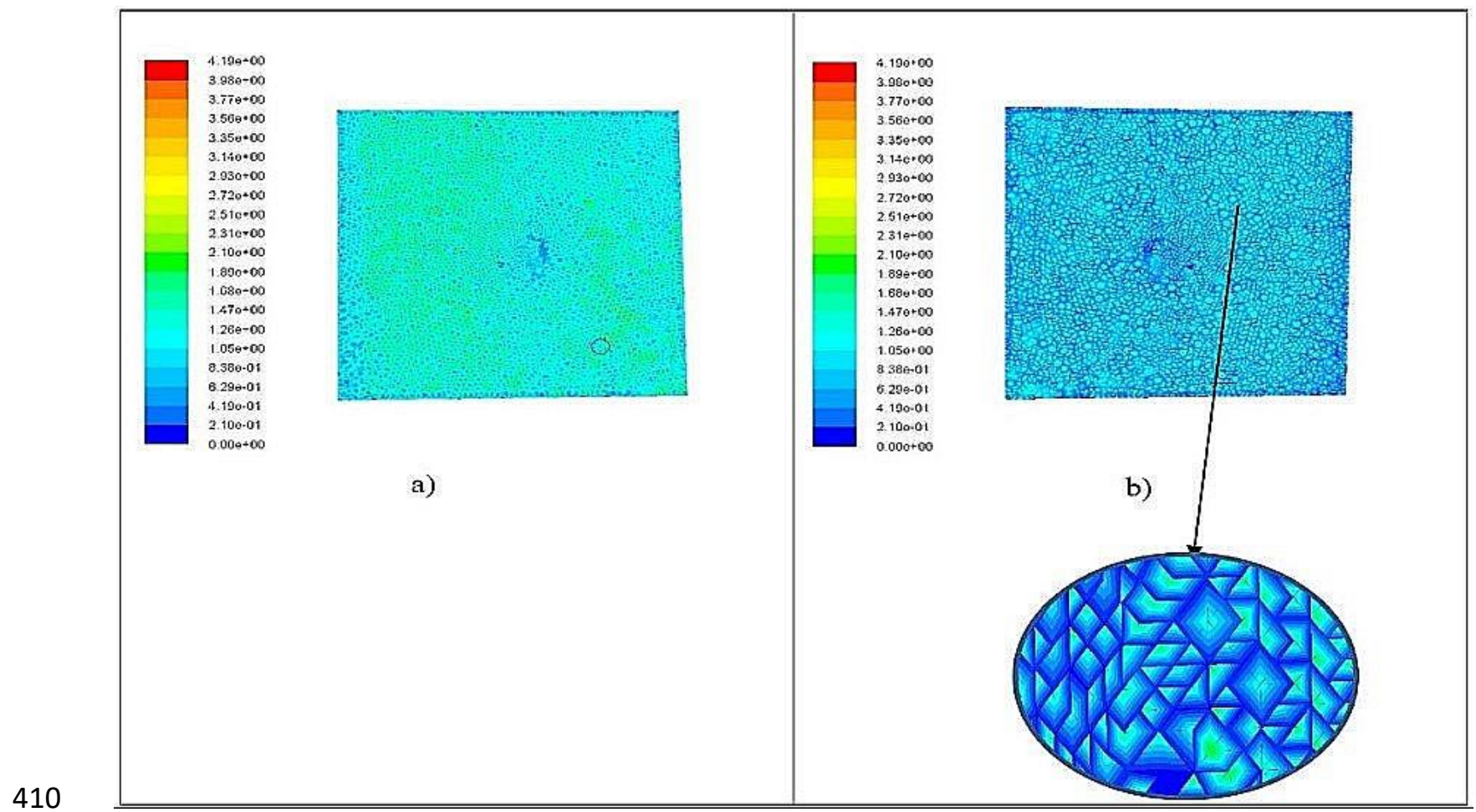

411 Fig. 25: Membrane water content of the fuel cell using dry oxygen a) anode region b)
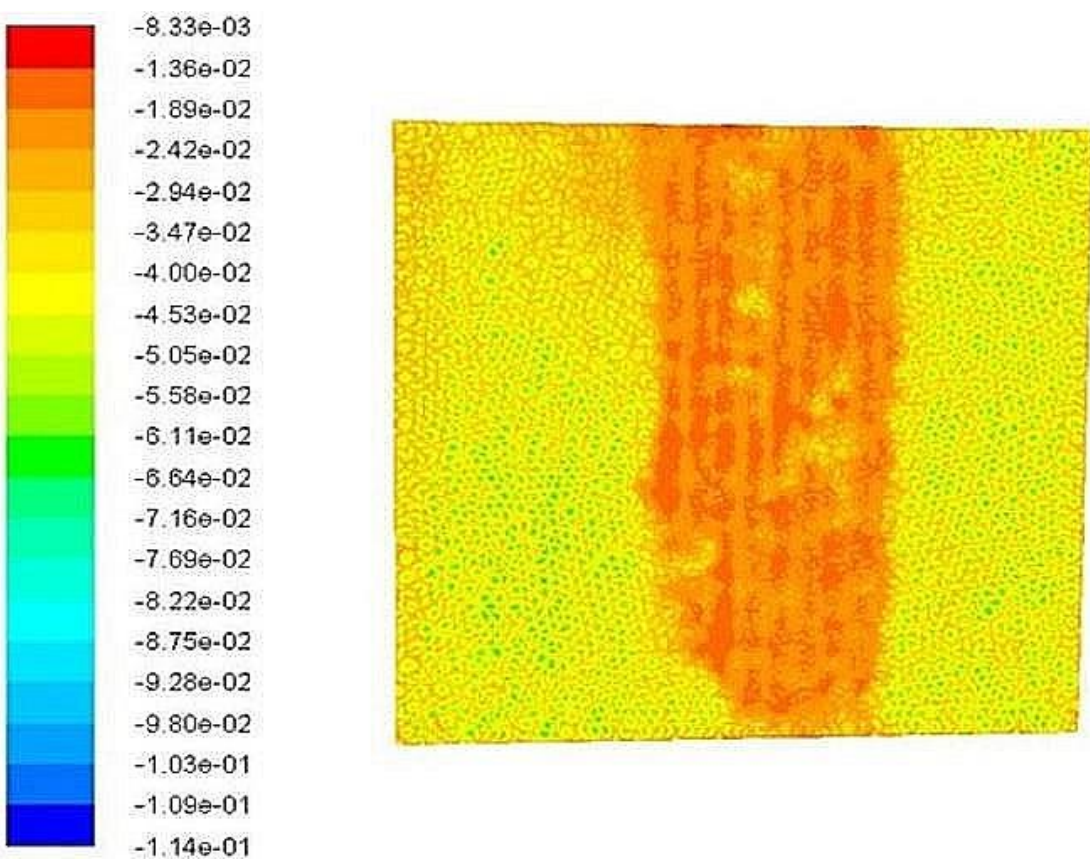

Fig. 26: Protonic potential of the fuel cell using dry oxygen gas 


\subsection{Performance of the fuel cell using $100 \% \mathrm{RH}$ oxygen}

418 Using $100 \% \mathrm{RH}$ oxygen showed high performance characteristics very similar to those 419 obtained using air with $100 \%$ RH humidity.

420 This work validate the previous postulated hypotheses to explain the high performance of using

421 humidified oxygen as shown by the contours obtained from the current flux density magnitude 422 plots shown in Fig. 27.

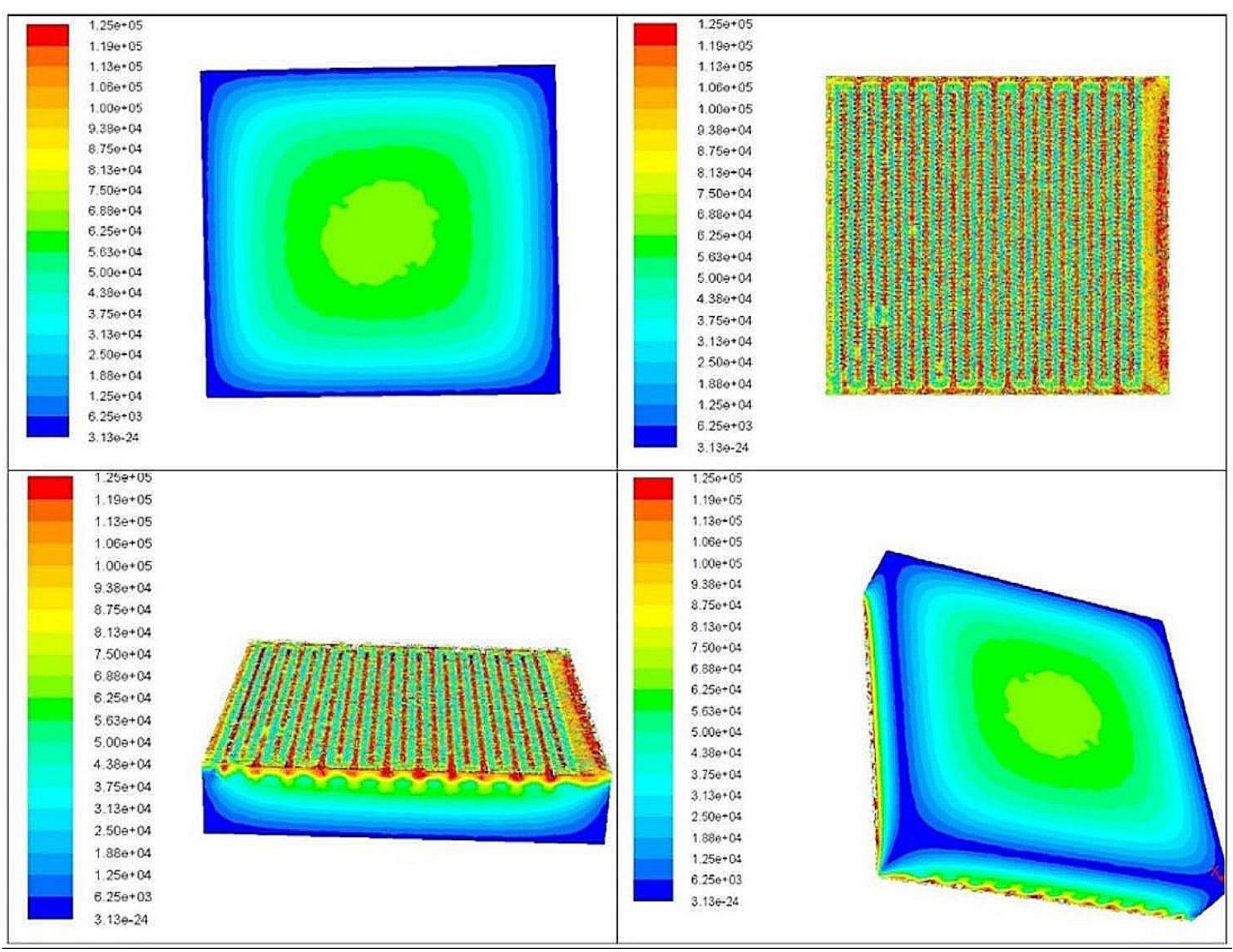

Fig. 27: Current flux density magnitude using 100\%RH oxygen

425 Another reason for the high performance of the fuel cell using humidified oxygen is the easy

426 flow of protons from the anode to the cathode due to high membrane hydration as shown in

427 Fig. 28. Once the membrane is well humidified with a good cell operating temperature, the fuel

428 cell will perform better at its peak. 
429

430

431 Fig. 29 and Fig. 30 shows the polarization curve for comparing the various humidification

432 conditions used in this investigation as well as the power density plots for each conditions, and

433 these are compared with experimental results. It can be observed that the $100 \% \mathrm{RH}$ oxygen 434 performed better followed by the $100 \% \mathrm{RH}$ Air and the $50 \% \mathrm{RH}$ Air.

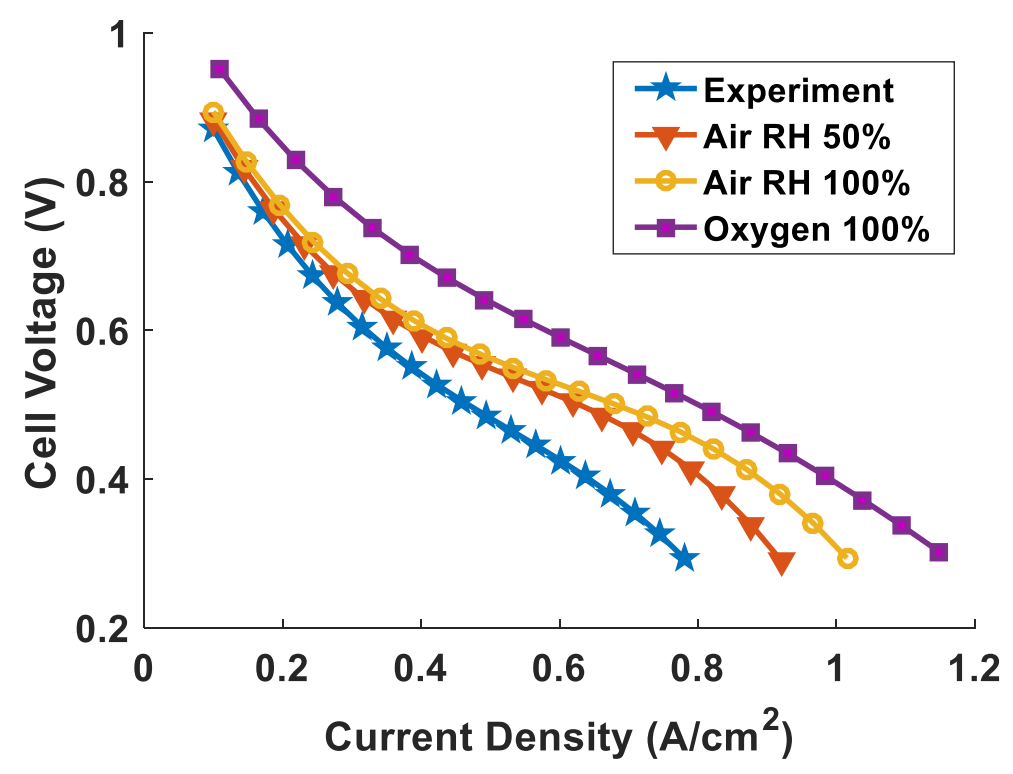

Fig. 29: Polarization curve of the performance of the fuel cell with respect to current density and voltage

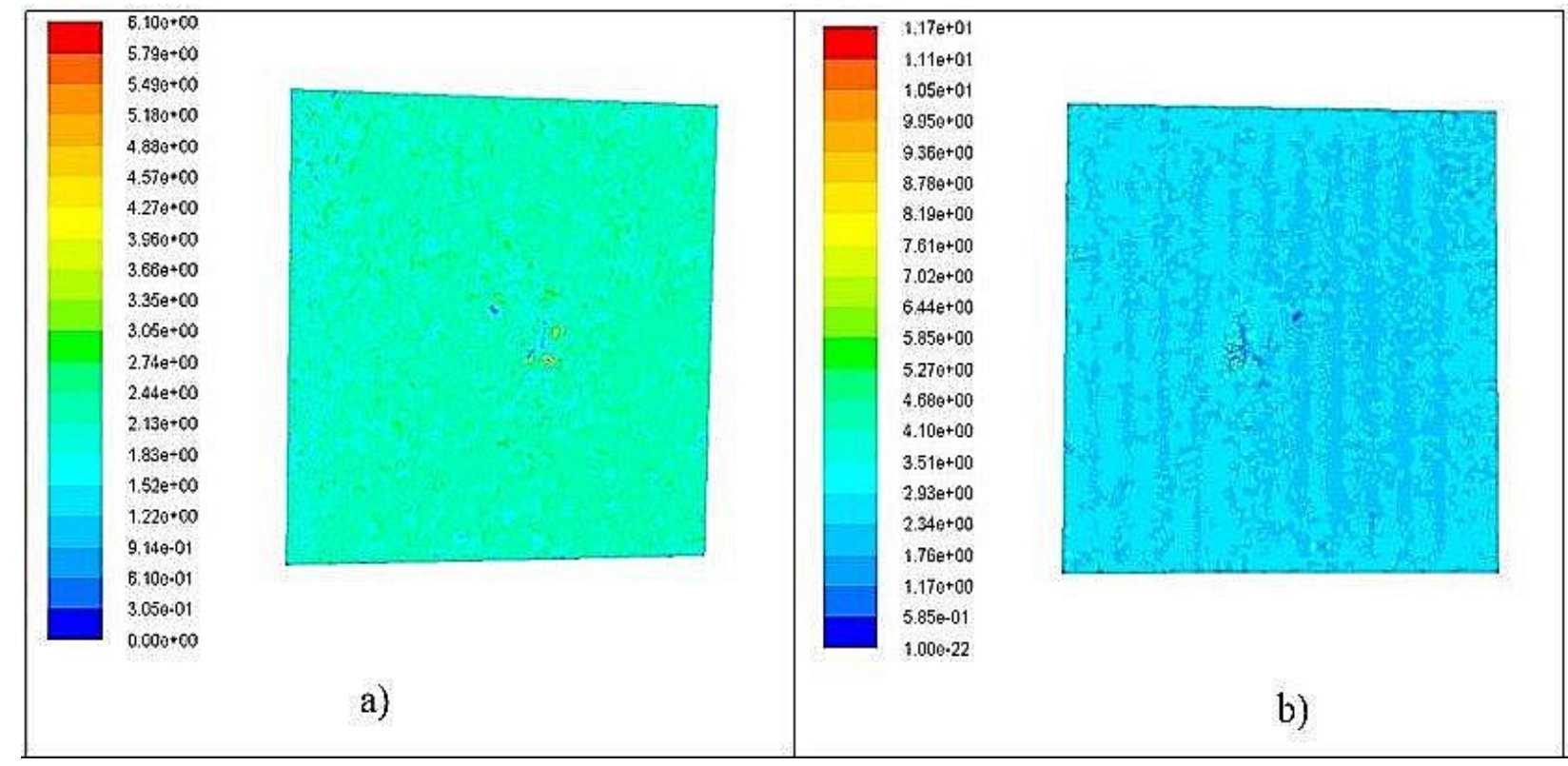

Fig. 28: a) Membrane water content b) Protonic conductivity using humidified oxygen. 


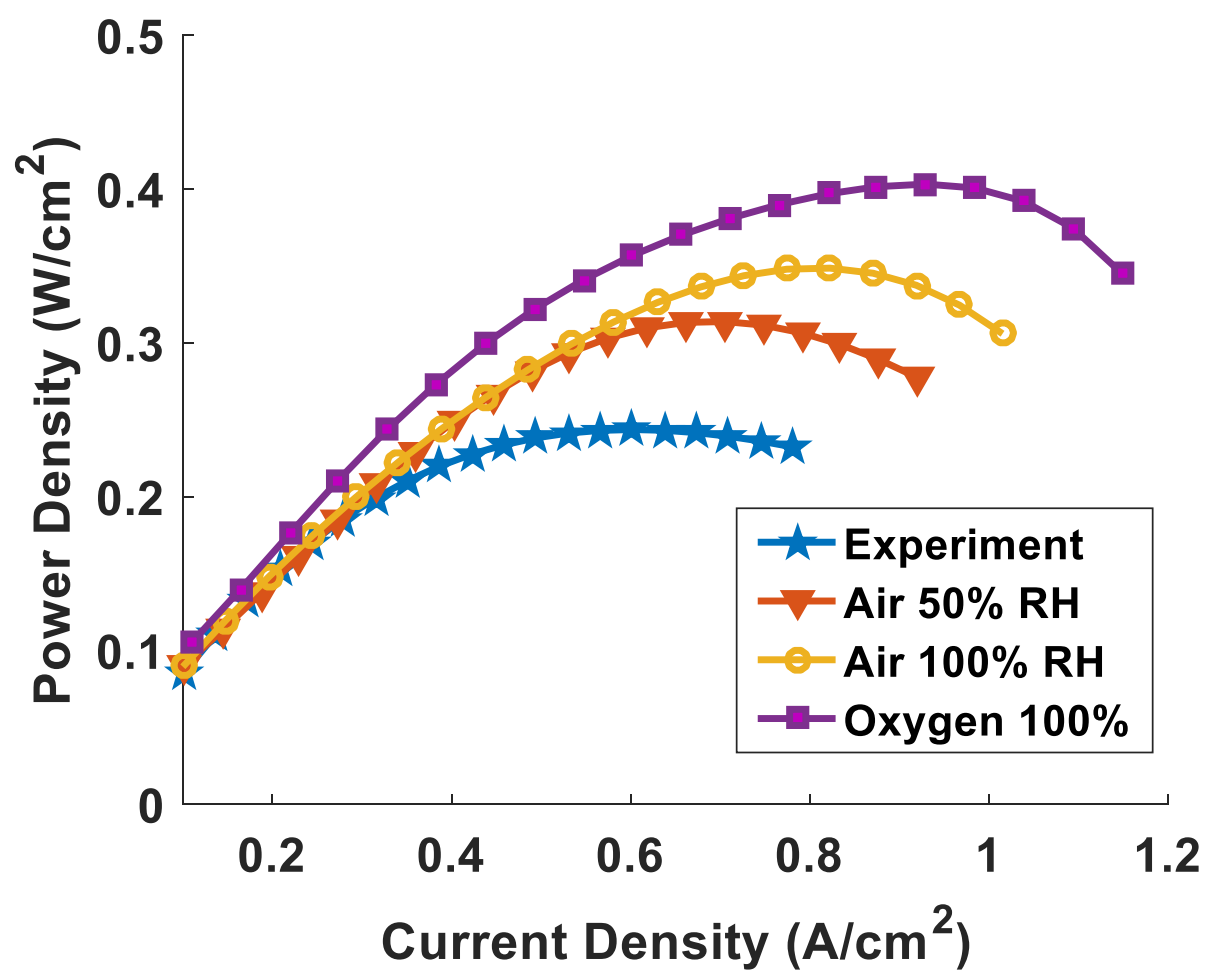

Fig. 30. Polarization curve for PEMFCs with respect to current density and power density

440 Given the closeness of the results, and due to the cost of operating fuel cell using pure

441 humidified oxygen, most researchers prefer using humidified air as it is readily available and 442 abundant.

\section{$443 \quad 3.0$ Conclusion}

444 This work presents both experimental and theoretical analysis of the performance of PEMFCs with respect to water formation and water management.

The experimental study used hydrogen and air and examined the performance with and without humidification and in all cases the results showed that humidification produced better overall performance in the fuel cell. Results obtained from $100 \%$ relative humidity of hydrogen and air are slightly better than those for $50 \%$ relative humidity indicating that dryer fuel or air result in water stripping from the membrane leading to increased protonic transport resistance and lower overall cell performance. This gives strong indication that to achieve the optimum performance from a PEM fuel cell, the proper level of humidification must be used to strike a balance between avoiding cell flooding and minimising protonic transport resistances. 
454 Experimental results from this study and from the literature were used to validate a newly 455 developed CFD simulation model which was then used to conduct parametric studies to 456 examine the effect of several operating parameters on the PEM fuel cells overall performance.

457 The results showed that the process of water management and overall fuel cell performance is 458 strongly impacted by the design of the fuel cell flow plate.

459 Simulation with $100 \%$ relative humidity of oxygen and air showed that the use of pure oxygen 460 provided slightly better results but they are not enough to justify the replacement of air by pure 461 oxygen given its cost and the ease of the use of air which is readily available and requires 462 minimal technical changes in the design of the fuel cells. Flow rate of gases and their flow 463 patterns also play important role in the improvement of the process of water management and 464 the overall fuel cell performance. 
[1]. T. Wilberforce, A. Baroutaji, B. Soudan, A.H. Al-Alami, A.G. Olabi, 2019, Outlook of carbon capture technology and challenges, Science of the Total Environment, 657, pp. 56-72

G. Olabi, Modelling and Simulation of Proton Exchange Membrane Fuel cell with Serpentine bipolar plate using MATLAB, International journal of hydrogen, 2017. DOI: 10.1016/j.ijhydene.2017.06.091.

[3] Tabbi Wilberforce, Zaki, El-Hassan, F.N. Khatib, A. Al Makyy, A. Baroutaji, J. G. Carton and A. G. Olabi. Developments of electric cars and fuel cell hydrogen electric cars. DOI: 10.1016/j.ijhydene.2017.07.054

[4]. A.Baroutaji, T. Wilberforce, M. Ramadan, A.G. Olabi, 2019, Comprehensive investigation on hydrogen and fuel cell technology in the aviation and aerospace sectors, Renewable and Sustainable Energy Reviews, 106, pp. 31-40.

[5]. E. Ogungbemi, O. Ijaodola, F.N. Khatib, T. Wilberforce, Z. El Hassan, J. Thompson, M. Ramadan, A.G. Olabi, 2019, Fuel cell membranes - Pros and cons, Energy, 172, pp. 155-172.

[6]. J.G. Carton and A.G. Olabi, 2017, Three-dimensional proton exchange membrane fuel cell model: Comparison of double channel and open pore cellular foam flow plates, Energy, 136, pp. $185-195$

[7].Tabbi Wilberforce, F .N. Khatib, O. S. Ijaodola, E. Ogungbemi, Zaki El-Hassan, A. Durrant, J. Thompson, A. G. Olabi. Numerical modelling and CFD simulation of a polymer electrolyte membrane (PEM) fuel cell flow channel using an open pore cellular foam material. Science of the total environment. Volume 678, 15 August 2019, Pages $728-740$.

[8]. A Baroutaji, JG Carton, AM Oladoye, J Stokes, B Twomey, A.G. Olabi, 2017, Ex-situ evaluation of PTFE coated metals in a proton exchange membrane fuel cell environment, Surface \& Coatings Technology, 323, pp. 10-17.

[9] Tabbi Wilberforce, F. N. khatib, O. Emmanuel, O. Ijeaodola, A. Abdulrahman, Ahmed AL Makky A. Baroutaji, A.G. Olabi. Experimental Study Of Operational Parameters On The Performance Of PEMFCS in Dead End Mode. Proceedings of SEEP2017, 27-30 June 2017, Bled Slovenia.

[10]. W. M. Yan, Y. C. C., M. S. Chin, S. C. Y, C. Falin. J power sources 2006:162:1157-64. [11]. W. Lin, H. Attila, Z. Tianhoug, L. Hongtan. Int J. Hydrogen Energy 2003:28:1263-72. 
[12]. P. Karthikeyen, L. Calvin, G. Lipscomb, S. Neelakrishnan, J. G. Abby, R. Anand. Experimental investigation of water impact on performance of proton exchange membrane fuel cells (PEMFC) with porous and non - porous flow channels. In: Proceedings of the ASME 2012

[13]. J. Park, X. Li. J. power sources 2007;163:853-63.

[14]. K. Atul, G. J. Ramana. J. power sources 2003; 113:11-8.

[15] Tabbi Wilberforce, A. Alaswad, A. Palumbo, A. G. Olabi, Advances in stationary and portable fuel cell applications, International Journal of Hydrogen Energy 41(37) March 2016.

[16]. T. Kanezaki, X. Li, J.J. Baschuk. J. Power sources 2006: 162: 415-25.

[17]. T. V. Nguyen. J Electrochem Soc 1996;05;143-8

[18]. Kazim A, H.T. Liu, P. Forges. J Appl Electrochem 1999; 29:1409-16.

[19]. A. P. Manso, F. F. Marzo, J. Barranco, X. Garikano, M. M. Garmendia. Rev Int. J Hydrogen Energy 2012;37: 15256 - 87.

[20]. N. Dilip, N. V. Trung. J. Power sources 2003; 115:66-80.

[21]. M.S. Wilson, T.E. Springer, J.R. Davey, S Gottesfeld. Alternative flow field and backing concepts for polymer electrolyte fuel cell. In: Gotesfeld S, Halpert G, Langrebe A, editors. Proton conducting membrane fuel cells. The electrochemical society proceedings series, 9523: 1995. P. 115 [pennington, $\mathrm{Nj}$ ].

[22]. J. G. Carton, A. G. Olabi. Design of experiment study of the parameters that affect performance of three flow plate configurations of a proton exchange membrane fuel cell. Energy. Volume 35, Issue 7, July 2010, Pages 2796 - 2806.

[23]. A. Cano, A. H Guerrero, S. M. R. Von, C. E. D. Ascencio, J. C. R. Arana. Energy 2016; 101:252-65.

[24] Tabbi Wilberforce, F. N. Khatib, Ahmed Al Makky, A. Baroutaji, A.G. Olabi Characterisation Of Proton Exchange Membrane Fuel Cell Through Design Of Experiment (DOE). Proceedings of SEEP2017, 27-30 June 2017, Bled, Slovenia

[25]. I Khazae, H. Sabadbanfan. Energy 2016;101:252-65.

[26]. L. Rostami, P. M. Nejad, A. Vatani. Energy 2016: 97:400-10.

[27] B. Nastasi, G. L. Basso. Hydrogen link to heat and electricity in the transition towards future smart energy systems. Energy 2016 Apr. 22. 
547 [29]. H. Liu and P. Li, "Even distribution/dividing of single phase fluids by symmetric bifurcation of flow channels" International Journal of Heat and Fluid Flow, 40, pp 165-179, 2013.

550 [30]. H. Liu, P. Li and J.V. Lew,"CFD study on flow distribution uniformity in fuel distributors having multiple structural bifurcations of flow channels", International Journal of Hydrogen Energy, 35 (17), pp 9186-9198, 2010.

[31]. G.M. Imbrioscia and H.J. Fasoli, "Simulation and study of proposed modifications over straight-parallel flow field design”, International Journal of Hydrogen Energy, 39 (16), pp 8861-8867 (2014).

556 [32]. E. Hontanon, M. J. Escudero, C. Bautista, P. L. Garcia- Ybarra, and L. Daza, 557 "Optimisation of flow-field in polymer electrolyte membrane fuel cells using computational fluid dynamics techniques." Journal of Power Sources, 86(1), pp 363- 368, 2000. [33]. M. Mohammadi, G.N. Jovanovic and K.V. Sharp "Numerical study of flow uniformity and pressure characteristics within a microchannel array with triangular manifolds" Computers \& Chemical Engineering, 52, pp 134- 144, 2013. bipolar plates: Part II. Flow through the diffusion layer", Journal of Power Sources, 179 (2), pp 711-722, 2008.

[35]. F. Barreras, A. Lozano, L. Valiño, C. Marín, A. Pascau, "Flow distribution in a bipolar plate of a proton exchange membrane fuel cell: experiments and numerical simulation studies", Journal of Power Sources, 144 (1), pp 54-66, 2005. [36]. Arvay, A. et al., 2011. Convergence criteria establishment for 3D simulation of proton exchange membrane fuel cell. International Journal of Hydrogen Energy, 37(3), pp.2482-2489. Available at: http://dx.doi.org/10.1016/j.ijhydene.2011.11.005.

571 [37]. Versteeg HK, Malalasekera W. An introduction to computational fluid dynamics: the 572 finite volume method. 2nd ed. Pearson Education; 2007.

573 [38] Iranzo, A. et al., 2010. Numerical model for the performance prediction of a PEM fuel cell. Model results and experimental validation. International Journal of Hydrogen Energy, 35(20), pp.11533-11550.

[39] T. Wilberforce, A. Al Makky, A. Baroutaji, R. Sambi and A.G Olabi, Optimization of 578 bipolar plate through computational fluid dynamics simulation and modelling using nickle 
579 open pore cellular foam material, International conference on renewable energies and power 580 quality (ICREPQ’17), ISSN 2171-038X, No 15 April 2017

581 [40] Cheng, C.-H., Lin, H.-H. \& Lai, G.-J., 2007. Design for geometric parameters of PEM 582 fuel cell by integrating computational fluid dynamics code with optimization method. Journal 583 of Power Sources, 165(2), pp.803-813.

584 [41] Giri, P. K. and Banerjee. J. Introduction to statistics. ISBN: $978-81-89781-56-9$. 


\section{Nomenclature}

$\begin{array}{cl}\varphi & \text { Rate of change quantity } \\ \varnothing & \text { Momentum } \\ V & \text { Volume } \\ T_{\varphi} & \text { Diffusivity coefficient } \\ S & \text { Source term } \\ \mu & \text { Mixture viscosity } \\ k & \text { Catalyst and GDL permeability } \\ k_{e f f} & \text { Effective conductivity } \\ h_{i} & \text { Species enthalpy } \\ j_{i} & \text { Species flux density } \\ \sigma & \text { Electrical conductivity } \\ \emptyset_{m e m} & \text { Membrane phase potential } \\ \emptyset_{S o l} & \text { Solid phase potential } \\ j & \text { Reference exchange current density } \\ \zeta & \text { Specific active surface area } \\ \gamma & \text { Concentration dependence } \\ \alpha & \text { Transfer coefficient } \\ \mathrm{F} & \text { Faradays constant } \\ {[\mathrm{A}]} & \text { Molar concentration of reactant at anode } \\ {[C]} & \text { Molar concentration of reactant at cathode } \\ \lambda_{m} & \text { Membrane water content } \\ T_{c e l l} & \text { Cell temperature } \\ \eta & \text { Local species overpotential } \\ V_{O C} & \text { Open circuit voltage } \\ p_{u} & \text { Upstream pressure } \\ p_{d} & \text { Downstream pressure } \\ k_{c a} & \text { Nozzle constant } \\ F_{a n} & \text { Input flow rate at anode } \\ k_{a n} & \end{array}$




$\begin{array}{cl}P_{a n} & \text { total pressure in anode } \\ P_{\text {sat }} & \text { Saturated vapour pressure } \\ P_{\mathrm{H}_{2} \mathrm{O} \_n} & \text { Water vapour pressure at anode } \\ P_{c a} & \text { total pressure in cathode } \\ P_{\mathrm{H}_{2} \mathrm{O}_{-} \mathrm{ca}} & \text { Water vapour pressure at cathode } \\ V_{a n} & \text { Volume of anode } \\ V_{c a} & \text { Volume of cathode } \\ F_{c a} & \text { Input flow rate at cathode }\end{array}$




\section{Appendix A: Numerical Modelling.}

587 The simulation process was conducted in four stages. In the first stage a model geometry of the 588 fuel cell was created using Solid Works 2016 then saved in Parasolid format.

589

590

591

592

593

594

595

596

597

598

599

600

601

602

603

604

605

606

607

608

609

610

611

612
In the second stage a mesh was generated using ANSYS ICEM CFD. The various layers in the fuel cell were carefully defined in the mesh and the boundary conditions for each of the 9 layers in the fuel cell were properly defined. Also the inlet and outlet boundary conditions of the geometry were defined in the software. The flow direction was carefully identified as any discrepancy in the flow direction will prevent the convergence of the calculations. The operating cell temperature and pressure were also specified.

In the third stage, the ANSYS Fluent solver is used to all the governing equations that represents the conservation of mass, momentum and energy in the Cartesian plane $(\mathrm{x}, \mathrm{y}, \mathrm{z})$, as well as the equations that account for electrochemical reactions, currents and the species taking part in the reactions.

The last stage is post processing where the results obtained from the simulation were processed to provide the necessary information for the analysis. These include current density, power density, species concentrations (hydrogen, oxygen and water), protonic conductivity and the pressure drop in the fuel cell that aid in the analysis of the performance of the PEM fuel cell.

\section{Design of the Geometry:}

The geometry was created using Solid Works 2016 as explained earlier. The geometry has nine layers in all representing the entire single stack fuel cell. These layers were initially created as a 2D diagram then converted to 3D using the extrude command in Solid Works. All the nine layers were then assembled together using the mating command. The nine layers are the anode current collectors, anode channel, anode diffusion layer, anode catalyst layer, membrane, cathode catalyst layer, cathode diffusion layer, cathode Channel and cathode current collector. Fig. A1 shows one of the assembly layers in solid works. 


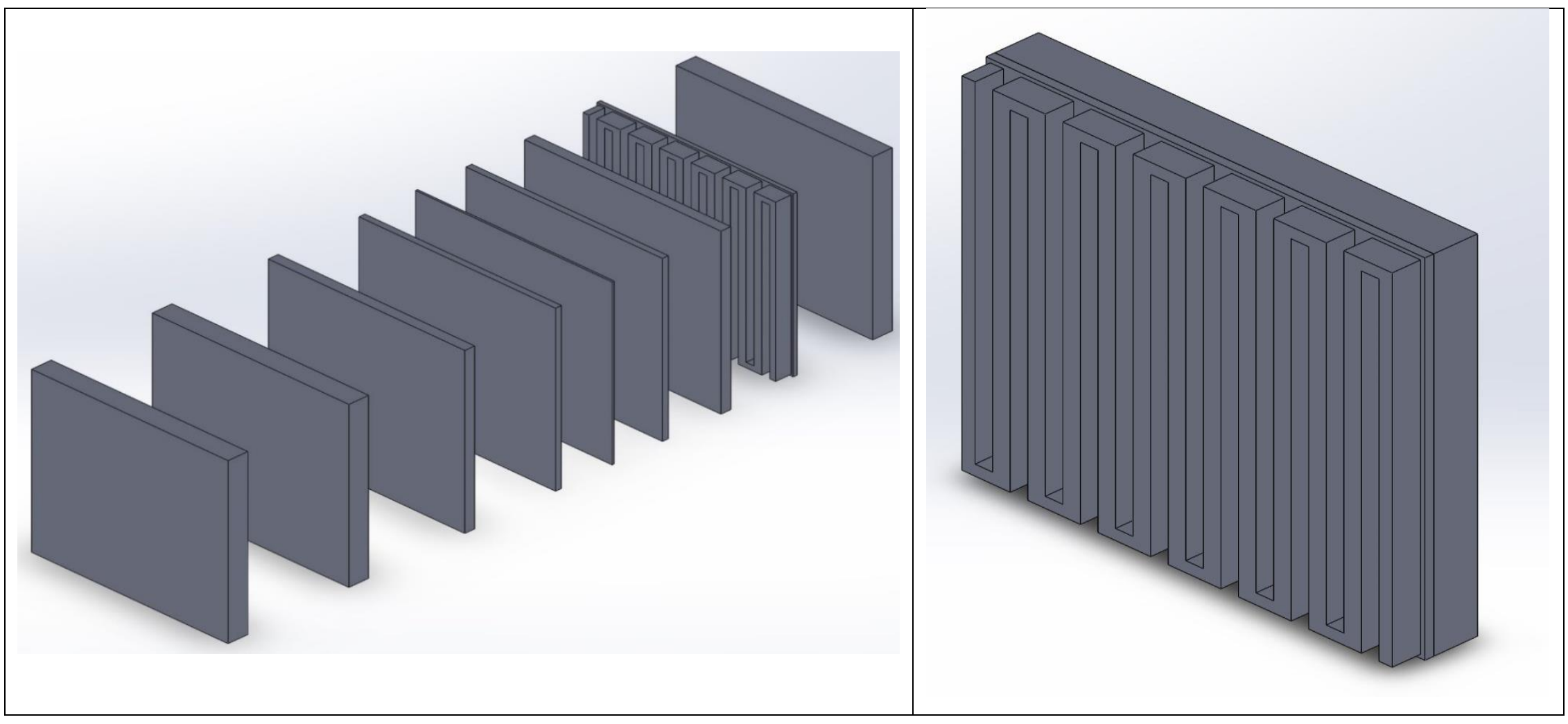

Fig. A1: Exploded View of Fuel Cell Assembly with Round Serpentine Flow Plate Design in Solid Works 
618 The various dimensions for each layer are clearly specified in Table A1. The serpentine design 619 that was used during the simulation was made up of a single channel just like what is on the market 620 to clearly differentiate the effect of each of the humidification condition on the fuel cell 621 performance.

622 Table A1. The dimensions for the modelled PEMFC

\begin{tabular}{|c|c|c|}
\hline Layers & Dimensions & Units \\
\hline Thickness of the membrane & 0.05 & $\mathrm{~mm}$ \\
\hline Catalyst layer thickness & 0.15 & $\mathrm{~mm}$ \\
\hline $\begin{array}{l}\text { Gas diffusion layer } \\
\text { thickness }\end{array}$ & 0.5 & $\mathrm{~mm}$ \\
\hline Width of the flow channel & 1.99 & $\mathrm{~mm}$ \\
\hline Land to width & 1.99 & $\mathrm{~mm}$ \\
\hline $\begin{array}{l}\text { Width of the current } \\
\text { collector }\end{array}$ & 2 & $\mathrm{~mm}$ \\
\hline Inclination & 5 & $\operatorname{deg}$ \\
\hline
\end{tabular}

623

624

625

626

627

628

629

630

631

632

633

634

635

636

\section{Meshing of the Geometry}

One of the key conditions that would aid in confirming the validity of the simulation results is the quality of the mesh. An improperly meshed geometry will not simulate the geometry and the system behaviour accurately.

The mesh was developed by considering each layer separately as they have different dimensions particularly with the thickness and channel length. Using the blocking method, each layer is meshed separately. This approach allowed for better definition of the mesh elements shapes and sizes allowing for the creation of hexahedral elements to better define the mesh to capture the thermal and hydraulic behaviour of the fuel cell as well as the electrochemical reactions. Mesh independency, or convergence tests, were then performed to ensure that the model results are independent of the number or size of the elements of the grid. The initial mesh tests had 2015321 elements, 2517821 elements and 3010212 elements. It was observed that above 2,517821 the results were grid independent. The voltage difference obtained as the mesh elements increased 
637 above 2517821 was less than $1 \%$ as can be seen in Fig. A2. The mesh convergence studies were 638 repeated for all the designs used in this study. The discretization of the cells was also done using 639 ICEM CFD for building the unit cells. The simulation of PEMFCs is complex and requires the 640 computational grid elements to be of very good quality if reliable results is to be obtained. This is 641 also important as it impacts on solver stability during the solution process [34] and the 642 computational resources required to achieve convergence and better accuracy.

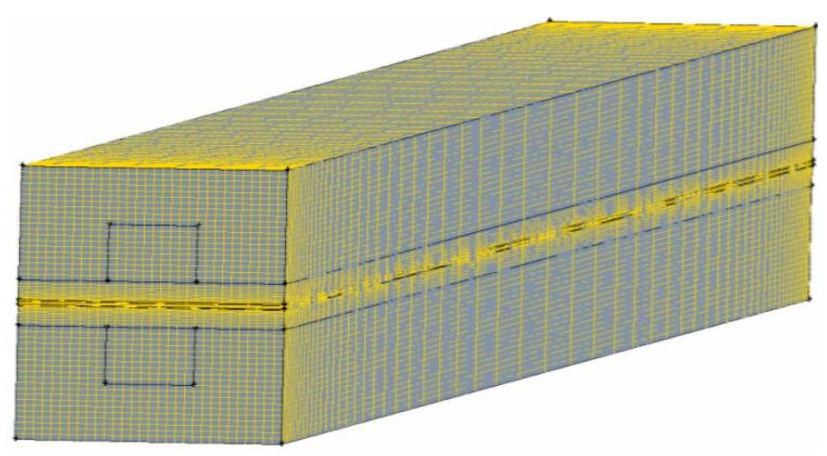

Fig. A2. Types of mesh applied to simulation.

646 It is commonly believed that an increase in the number of elements (fine mesh) implies that the 647 results generated will be of better accuracy but this approach requires large resources to carry out 648 the simulations. A more efficient approach is to refine the mesh using the tools providing in the 649 meshing software to obtain better quality cells and mesh and to strike a good balance between the 650 acceptable level of accuracy and the necessary computational time. It is therefore imperative that 651 grid independent analysis is properly conducted to ensure the validity of the simulation results. 652 The histogram of Fig. A3 shows that above 2500000 elements the current being generated was the 653 same for a cell voltage of 0.4 . 


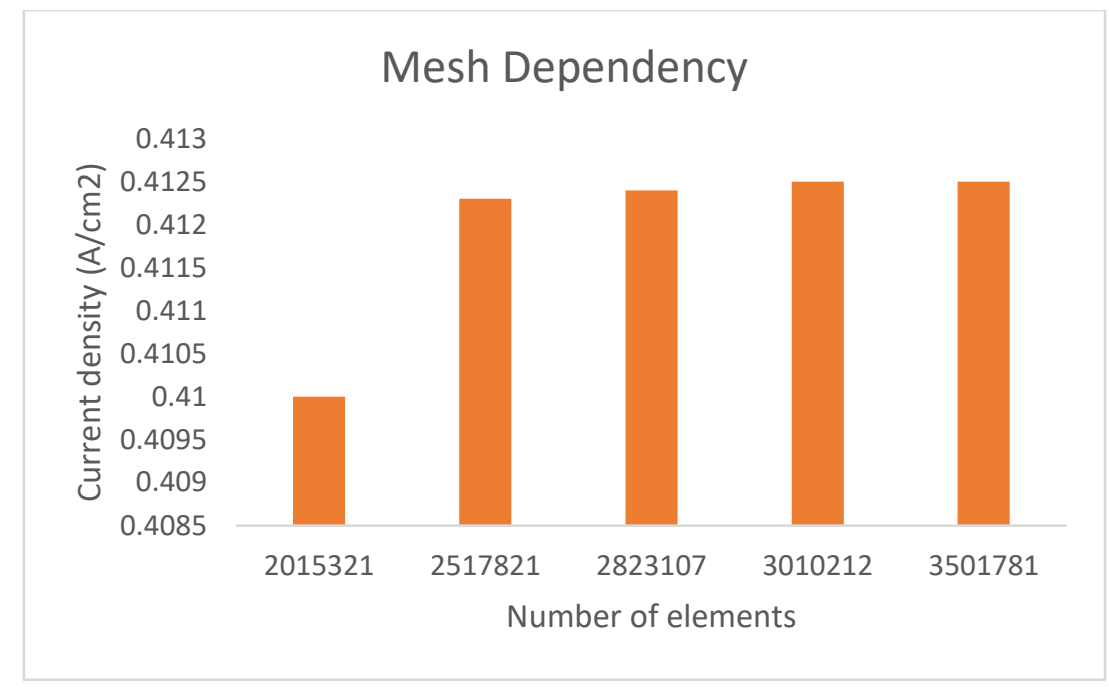

655

Fig. A3: Mesh dependency analysis.

656 Fuel Cell Mathematical Model:

657 A fuel cell is an energy conversion device used for the conversion of the chemical energy in fuel(s)

658 directly into electrical energy. The fuel cell has the triple-phase boundary condition referred to as

659 the catalyst layer. Fig. A4 shows the schematic diagram of a typical configuration of PEM fuel 660 cell as illustrated in ANSYS Fluent 15.0 Fuel Cell module manual [39]. The computational fluid 661 domain is also made up of the ionic conducting electrolyte. From Fig. A3, it can be seen that the 662 flow of hydrogen into the fuel cell occurs via the anode region. The anode region reactive gas then 663 diffuses through the pores of the GDL before reaching the catalyst active sites of the fuel cell. On 664 reaching the catalyst, it dissociates into protons and electrons with the former flowing through the 665 membrane towards the cathode region and the electrons flowing through an external load circuit 666 producing the current. The electrons then flow from the anode electrode, via the current collectors 667 and GDL to the cathode. Hydrogen ions, electrons and oxygen then combine at the cathode 668 forming water. 


$$
H_{2} \leftrightarrow 2 H^{+}+2 e^{-} \quad \text { (Anode Triple phase boundary) }
$$

$$
1 / 2 \mathrm{O}_{2}+2 e^{-}+2 \mathrm{H}^{+} \leftrightarrow \mathrm{H}_{2} \mathrm{O} \text { (Cathode Triple pahse boundary) }
$$
layers (TPB) for the anode and cathode.

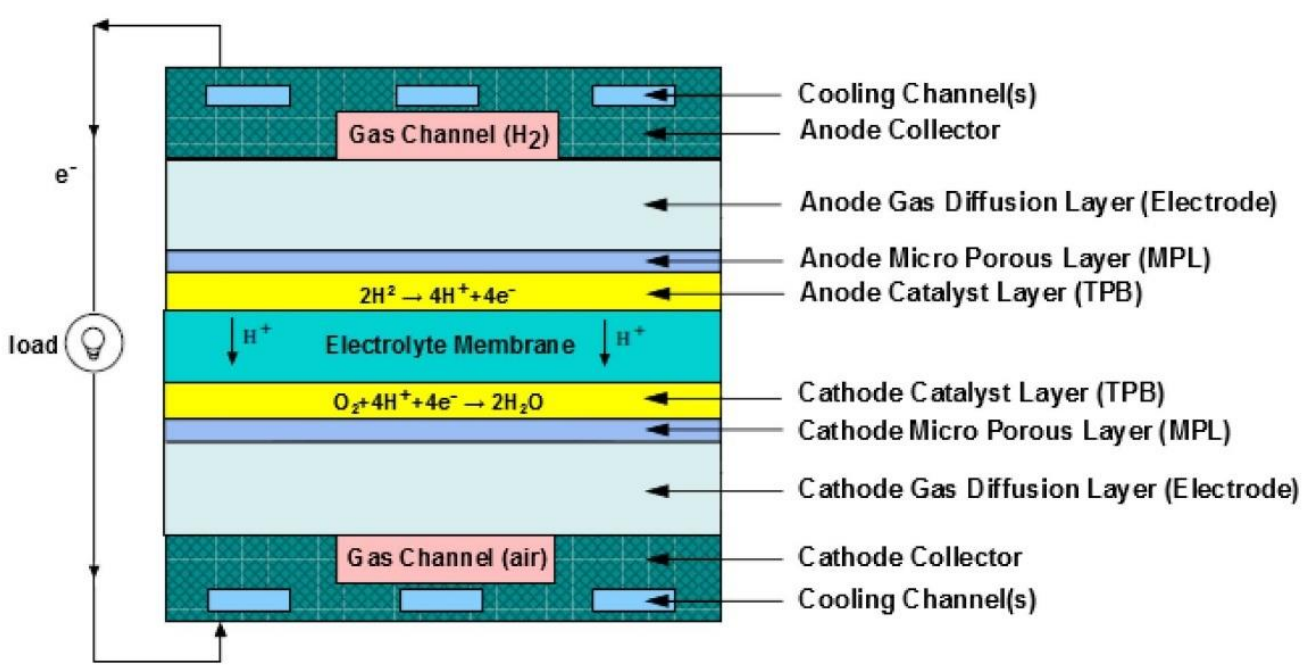

Fig. A4. Diagram of a proton exchange membrane fuel cell [39]

Two electric potential fields are solved in fuel cell Ansys Fluent. One of the potentials is mathematically computed in the electrolyte as well as the catalyst layer whiles the other computation is solved for the catalyst layer, the electrode being porous in nature and current collectors. The determination of rate of electrochemical reaction is solved in the catalyst region.

By varying the electric potential for the cathode region whiles grounding that of the anode region to zero, the current density value can easily be computed. Similarly, it is possible to determine the cell voltage by specifying the cell current. Eqn. A1 and Eqn. A2 show the triple phase boundary

Electrons flow through the external circuit to the cathode while the protons $\left(\mathrm{H}^{+}\right)$diffuse through the membrane from the anode triple phase boundary to the cathode triple phase boundary creating electrical circuit. Water vapour pressure exceeds the saturation pressure producing liquid water as excess water is produced around the cathode region at high current densities due to osmotic drag, 


$$
\frac{\partial}{\partial t} \int p \varphi d V+\oint p \varphi V \cdot d A+\oint T_{\varphi} \nabla_{\varphi} \cdot d A=\int S_{\varphi} d V
$$
The conservation equation explains how the rate of change of a quantity $\varphi$ in a control volume 699 plus transport due to convection and species diffusion in and out of the control volume are the 701

702

$$
\nabla(\vec{V})=S_{m}
$$

705 Where $S_{m}$ is the species sources term and $(\vec{V})$ is the fluid velocity vector.

Eqn. A5 shows steady state flow momentum equation:

$$
p \frac{(\vec{V})}{d t}=-\nabla \cdot p+\mu\left(\nabla^{2} \cdot \vec{V}\right)+S_{p}
$$
where $\mu$ is mixture viscosity, $\mathrm{p}$ the static pressure, $\rho$ is the density and $S_{p}$ is source term which is given by: 


$$
S_{p}=-\left(\frac{\mu}{k}\right)
$$

710 where $\mu$ is the gas velocity, $\mathrm{k}$ is the catalyst layer and GDL permeability, $(\vec{V})$ is the superficial 711 velocity.

712 The equation for the energy is also solved using the steady state energy equation as shown in Eqn. 713 (A7).

$$
\nabla \cdot\left[\vec{V}\left(\rho_{t}+p\right)\right]=\nabla\left(k_{e f f} \nabla T-\sum_{i} h_{i} \overrightarrow{J_{l}}\right)
$$

715 The total energy is represented by E, $k_{\text {eff }}$ is the effective conductivity, $h_{i}$ is species enthalpy and $J_{i}$ 716 is species flux density. Species transport equation also considered mass conservation for the type 717 of gas to focus on the mass fraction of each of the species $y_{i}$. Eqn. A8 shows the species transport 718 equation.

$$
\nabla \cdot\left(\rho \vec{V} y_{i}\right)=-\nabla \overrightarrow{J_{l}}+S_{i}
$$

721 The source term of the species is represented by $S_{i}$, and $\vec{J}_{l}$ is the species flux density. Since the 722 fluid flow through the flow field is laminar, diffusion is given by:

$723 \quad \vec{J}_{i}=-p D_{i} \cdot \nabla \cdot y_{i}$

$$
h_{i} \overrightarrow{J_{l}}=-p D_{i} \cdot \nabla \cdot y_{i}
$$

724 where $D_{i}$ is the diffusion coefficient for the species $i$.

725 The following assumptions were made prior to the simulations. All the reactant gases are assumed 726 be behave as ideal gases.

- Fluid flow is assumed to be incompressible, laminar and steady.

- The temperature was maintained at $353 \mathrm{~K}$ for all the simulation work.

- The isotropic porous zones considered during the simulation were the catalyst layers, GDL and the electrolyte. 
- The active region where electrochemical reaction occurred was also considered as the TPB or the catalyst layer.

- Gravitational effects were negligible.

- Transfer of water through the electrolyte was as a result of back diffusion and electro osmotic drag only.

Fig. A5 shows the boundary conditions for the electric potential in PEM FC. The computation of the rates of the anodic and cathodic reactions is the main challenge with the electrochemical simulations. The surface potential is the main driving force behind these reactions. The surface potential is simply the difference between the phase potential of the solid and the phase potential of the electrolyte/membrane. Two equations are solved for the fuel cell model. The first equation (Eqn. A10) accounts for electrons $\left(e^{-}\right)$transport through the solid conducting materials such as the current collectors and solid grids of the porous media, whiles the other potential Eqn. (A4) represents the protonic transport of $\mathrm{H}^{+}$and $\mathrm{O}^{-2}$.

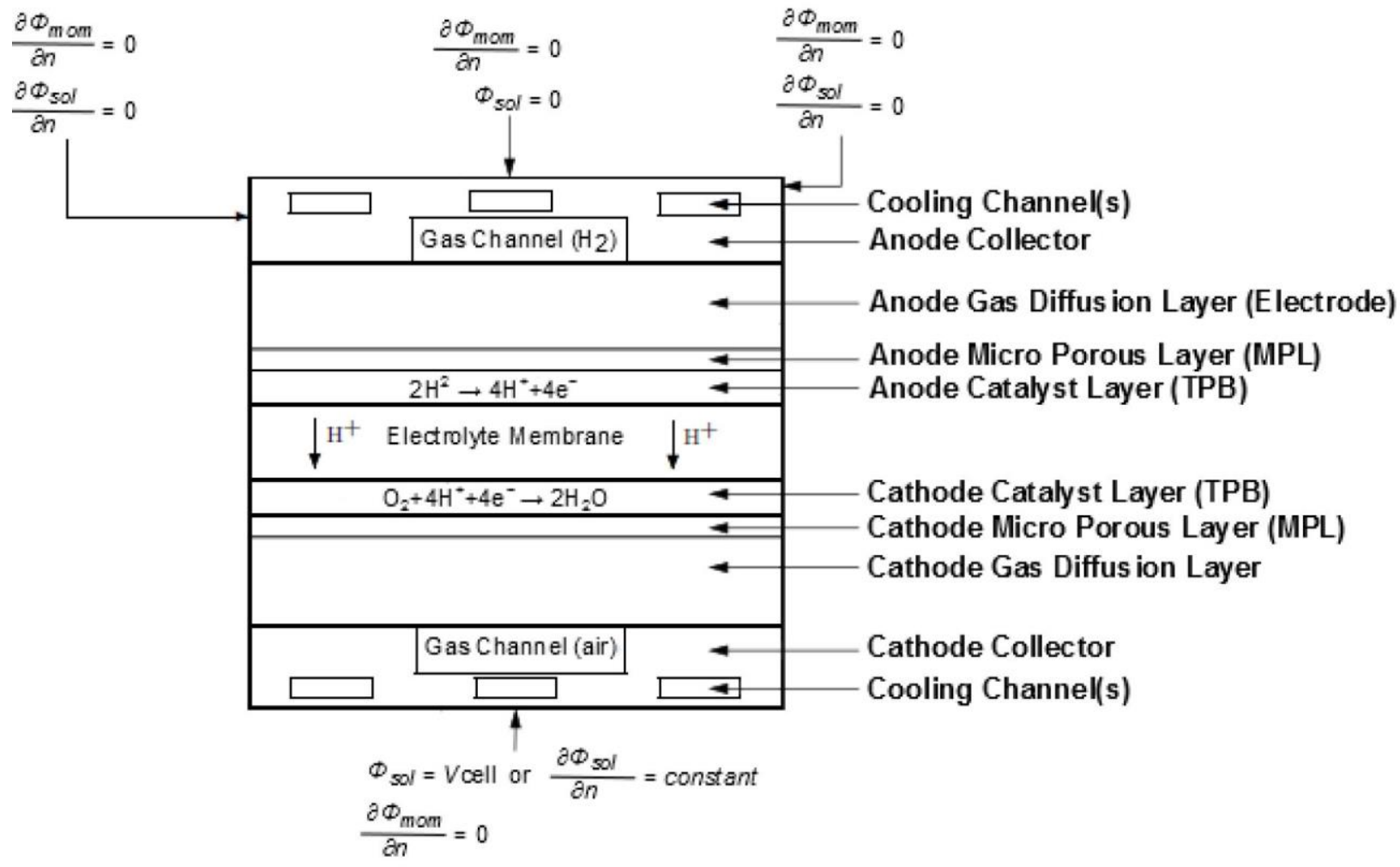

Fig. A5: Boundary conditions for the Electric potential (Solid Membrane)[40] 


$$
\nabla \cdot\left(\sigma_{S o l} \nabla \emptyset_{S o l}\right)+R_{S o l}=0
$$

$$
\nabla \cdot\left(\sigma_{m e m} \nabla \emptyset_{m e m}\right)+R_{m e m}=0
$$

750

751

752

753

754

755

756

757

758

759

760

761

762

763

764

765

766

$767=(-$

768

$$
R_{a n}=\left(\zeta_{a n} j_{a n}^{r e f}\right)\left(\frac{[A]}{[A]_{r e f}}\right)^{\gamma_{a n}}\left(e^{\alpha_{a n} F \eta_{a n} / R T}-e^{-\alpha_{c a t} F \eta_{a n} / R T}\right)
$$

$769=$

$$
R_{c a t}=\left(\zeta_{c a t} j_{c a t}^{r e f}\right)\left(\frac{[C]}{[C]_{\text {ref }}}\right)^{\gamma_{c a t}}\left(-e^{+\alpha_{a n} F \eta_{c a t}-R T}-e^{-\alpha_{c a t} F \eta_{c a t} / R T}\right)
$$


771 where $j^{\text {ref }}$ is the reference exchange current density for the active surface area $\left(\mathrm{A} / \mathrm{m}^{2}\right), \zeta$ is the 772 specific active surface area $(1 / \mathrm{m}),[]$ and []$_{\text {ref }}$ indicate local species concentration and reference 773 value $\left(\mathrm{kmol} / \mathrm{m}^{3}\right)$, respectively. $\gamma$ is concentration dependence $\alpha$ is the transfer coefficient 774 (dimensionless) and $\mathrm{F}$ is Faraday's constant $\left(9.65 \times 10^{7} \mathrm{C} / \mathrm{kmol}\right)$

775 Tafel formula is the simplified version of the Butler-Volmer equation and is shown in Eqn. A14 776 and A15.

777

$$
R_{a n}=\left(\zeta_{a n} j_{a n}^{r e f}\right)\left(\frac{[A]}{[A]_{\text {ref }}}\right)^{\gamma_{a n}}\left(e^{\alpha_{a n} F \eta_{a n} / R T}\right)
$$

$$
R_{\text {cat }}=\left(\zeta_{\text {cat }} j_{\text {cat }}^{r e f}\right)\left(\frac{[C]}{[C]_{\text {ref }}}\right)^{\gamma_{c a t}}\left(-e^{+\alpha_{a n} F \eta_{c a t} / R T}\right)
$$

781 To accurately calculate the transfer currents inside the catalysts layers in fuel cells, ANSYS Fluent 782 uses the Butler-Volmer equation. From Eqns. A12 - A15, the molar concentration of the reactant 783 species at anode and cathode electrodes are represented by [A] and [C] respectively. The A 784 represents the hydrogen concentration and the $\mathrm{C}$ is the concentration of oxygen. The local surface 785 overpotential driving force for the kinetics is denoted by $\eta$. The overpotential is also referred to as 786 the activation loss. The difference between the membrane potential and the solid potential is the 787 overpotential. The gain in electrical potential from moving from the anode electrode to the cathode 788 electrode is calculated by subtracting the open-circuit voltage $V_{O C}$ of the cathode electrode.

$$
\eta_{\text {an }}=\emptyset_{\text {Sol }}-\emptyset_{m e m}
$$

$$
\eta_{c a t}=\emptyset_{S o l}-\emptyset_{m e m}-V_{O C}
$$


792 Using volumetric species mass terms is also a method of adhering to mass conservation.

793

794

$$
S_{H_{2}}=-\frac{M_{W, H_{2}}}{2 F} R_{a n}<0
$$

795

796

$$
S_{O_{2}}=-\frac{M_{W, O_{2}}}{2 F} R_{c a t}<0
$$

797

$$
S_{\mathrm{H}_{2} \mathrm{O}}=-\frac{M_{W, \mathrm{H}_{2} \mathrm{O}}}{2 \mathrm{~F}} R_{a n}>0
$$

798

799 The species source term $\left(\mathrm{Kg} / \mathrm{s} . \mathrm{m}^{3}\right)$ in this case is represented by $S_{X}$ and $M_{W}$ is the species molecular 800 mass $(\mathrm{kg} / \mathrm{kmole})$. The equation has a negative sign indicating that the hydrogen and oxygen are 801 depleting by reaction while water is formed. Conservation of electric current is described by Eq. 802 A21 shown below.

803

804

$$
\int R_{a n} d V_{a n}=\int R_{c a t} d V_{c a t}
$$

805

806 The volumetric sources for thermal energy are needed because not all of the chemical energy is 807 converted to electrical work. The thermal energy equation is used to describe the process:

808

809

$$
S_{h}=h_{\text {react }}-R_{\text {an,cat }} \eta_{\text {an,cat }}+I^{2} R_{o h m}+h_{L}
$$

810 where the net rate of change in enthalpy $(\mathrm{J} / \mathrm{s})$ as a result of electrochemical reactions is represented

811 by $h_{\text {react }} . R_{a n, c a t} \eta_{a n, c a t}$ is the product of anode overpotential and transfer current or cathode 
812 potential and transfer current. $R_{o h m}$ is the conducting media ohmic resistivity and I is the current 813 (A). $h_{L}$ is the enthalpy change due phase change of water. The flow through the porous media of 814 the gas diffusion layers and catalyst layer was also modelled by adding a negative source that 815 represents the flow pressure drop into the species equations and computing species diffusivities. 816 Many mathematical expressions were used to represent each process occurring at each region in 817 the fuel cell as explained earlier. The continuity, momentum transport, energy, hydrogen transport 818 at the anode region, oxygen transport, water transport at both the anode and cathode region can all 819 be represented by mathematical expressions.

820 The earlier equations (A3-A22) can also be grouped into specific sections as indicated in Table 821 A2. 
Table A2: Governing equations of the fuel cell model.

\begin{tabular}{|c|c|c|}
\hline $\begin{array}{l}\text { Governing } \\
\text { Equations }\end{array}$ & Mathematical expressions & \\
\hline Continuity & $\frac{\partial(p \vec{u})}{\partial x}+\frac{\partial(p \vec{v})}{\partial y}+\frac{\partial(p \vec{w})}{\partial z}=S_{M}$ & $\mathrm{a}$ \\
\hline $\begin{array}{l}\text { Momentum } \\
\text { transport }\end{array}$ & $\begin{array}{l}u \frac{\partial(p \vec{u})}{\partial x}+v \frac{\partial(p \vec{u})}{\partial y}+w \frac{\partial(p \vec{u})}{\partial z}=\frac{\partial p}{\partial x}+\frac{\partial}{\partial x}\left(\mu \frac{\partial \vec{u}}{\partial x}\right)+\frac{\partial}{\partial y}\left(\mu \frac{\partial \vec{u}}{\partial y}\right)+\frac{\partial}{\partial z}\left(\mu \frac{\partial \vec{u}}{\partial z}\right)+S_{p x} \\
u \frac{\partial(p \vec{v})}{\partial x}+v \frac{\partial(p \vec{v})}{\partial y}+w \frac{\partial(p \vec{v})}{\partial z}=\frac{\partial p}{\partial x}+\frac{\partial}{\partial x}\left(\mu \frac{\partial \vec{v}}{\partial x}\right)+\frac{\partial}{\partial y}\left(\mu \frac{\partial \vec{v}}{\partial y}\right)+\frac{\partial}{\partial z}\left(\mu \frac{\partial \vec{v}}{\partial z}\right)+S_{p y} \\
u \frac{\partial(p \vec{w})}{\partial x}+v \frac{\partial(p \vec{w})}{\partial y}+w \frac{\partial(p \vec{w})}{\partial z}=\frac{\partial p}{\partial x}+\frac{\partial}{\partial x}\left(\mu \frac{\partial \vec{w}}{\partial x}\right)+\frac{\partial}{\partial y}\left(\mu \frac{\partial \vec{w}}{\partial y}\right)+\frac{\partial}{\partial z}\left(\mu \frac{\partial \vec{w}}{\partial z}\right)+S_{p z}\end{array}$ & $\mathrm{~b}$ \\
\hline Energy & $\frac{\partial(p C T)}{\partial x}+v \frac{\partial(p C T)}{\partial y}+w \frac{\partial(p C T)}{\partial z}=\frac{\partial}{\partial x}\left(k \frac{\partial T}{\partial x}\right)+\frac{\partial}{\partial y}\left(k \frac{\partial T}{\partial y}\right)+\frac{\partial}{\partial z}\left(k \frac{\partial T}{\partial z}\right)+S_{h}$ & $\mathrm{c}$ \\
\hline $\begin{array}{l}\text { Hydrogen } \\
\text { transport } \\
\text { (anode) }\end{array}$ & $\vec{u} \frac{\partial\left(p y H_{2}\right)}{\partial x}+\underset{v}{\rightarrow} \frac{\partial\left(p y H_{2}\right)}{\partial y}+\underset{w}{\rightarrow} \frac{\partial\left(p y H_{2}\right)}{\partial y}=\frac{\partial\left(\overrightarrow{J_{X, H_{2}}}\right)}{\partial x}+\frac{\partial\left(\overrightarrow{J_{y, H_{2}}}\right)}{\partial y}+\frac{\partial\left(\overrightarrow{J_{z, H_{2}}}\right.}{\partial z}+S_{H_{2}}$ & $\mathrm{~d}$ \\
\hline $\begin{array}{l}\text { Water } \\
\text { transport } \\
\text { (anode) }\end{array}$ & $\vec{u} \frac{\partial(\text { pyaw })}{\partial x}+\underset{v}{\rightarrow} \frac{\partial(\text { pyaw })}{\partial y}+\underset{w}{\rightarrow} \frac{\partial(\text { pyaw })}{\partial y}=\frac{\partial\left(\overrightarrow{J_{X, a w}}\right)}{\partial x}+\frac{\partial\left(\overrightarrow{J_{y, a w}}\right)}{\partial y}+\frac{\partial\left(\overrightarrow{J_{z, a w}}\right.}{\partial z}+S_{a w}$ & $\mathrm{e}$ \\
\hline
\end{tabular}




\begin{tabular}{|c|c|c|}
\hline $\begin{array}{l}\text { Oxygen } \\
\text { transport } \\
\text { (Cathode) }\end{array}$ & $\vec{u} \frac{\partial\left(p Y O_{2}\right)}{\partial x}+\underset{v}{~} \frac{\partial\left(p Y O_{2}\right)}{\partial y}+\underset{w}{~} \frac{\partial\left(p y O_{2}\right)}{\partial y}=\frac{\partial\left(\overrightarrow{J_{X, O_{2}}}\right)}{\partial x}+\frac{\partial\left(\overrightarrow{J_{y, O_{2}}}\right)}{\partial y}+\frac{\partial\left(\overrightarrow{J_{z, O_{2}}}\right)}{\partial z}+S_{O_{2}}$ & $\mathrm{f}$ \\
\hline $\begin{array}{l}\text { Water } \\
\text { transport } \\
\text { (Cathode) }\end{array}$ & $\vec{u} \frac{\partial(p y c w)}{\partial x}+\underset{v}{\rightarrow} \frac{\partial(p y c w)}{\partial y}+\underset{w}{\rightarrow} \frac{\partial(p y c w)}{\partial y}=\frac{\partial\left(\overrightarrow{J_{X, c w}}\right)}{\partial x}+\frac{\partial\left(\overrightarrow{J_{y, c w}}\right)}{\partial y}+\frac{\partial\left(\overrightarrow{J_{z, c w}}\right)}{\partial z}+S_{c w}$ & $\mathrm{~g}$ \\
\hline Source terms & $\begin{array}{l}S_{m}=S_{H_{2}}+S_{a w} \quad S_{m}=S_{O_{2}}+S_{c w} \\
S_{p x}=\frac{\mu \vec{u}}{k} \quad S_{p y}=\frac{\mu \vec{v}}{k} \quad S_{p z}=\frac{\mu \vec{w}}{k} \\
\overrightarrow{J_{i}}=-p D_{i} \nabla \cdot y_{i} \\
S_{h}=I^{2} R_{o h m}+h_{\text {react }}+\eta_{a c t} R_{a n, c a} \\
S_{\mathrm{H}_{2}}=-\frac{M_{\mathrm{H}_{2}}}{2 F} R_{a n} \\
S_{a w}=-\frac{M_{\mathrm{H}_{2} O}}{F} R_{a n} \\
S_{a w}=-\frac{M_{\mathrm{O}_{2}}}{4 F} R_{c a} \\
S_{c w}=-\frac{M_{\mathrm{H}_{2} O}}{2 F} R_{c a}\end{array}$ & $\begin{array}{l}\mathrm{i} \\
\mathrm{j}\end{array}$ \\
\hline
\end{tabular}




\begin{tabular}{|l|ll|l|}
\hline & $\nabla \cdot\left(\sigma_{\text {Sol }} \nabla \emptyset_{\text {Sol }}\right)+R_{\text {Sol }}=0$ & $\nabla \cdot\left(\sigma_{\text {mem }} \nabla \emptyset_{\text {mem }}\right)+R_{\text {mem }}=0$ & $\mathrm{P}$ \\
Charge & & & \\
\hline
\end{tabular}




\section{Boundary conditions}

826 The cell temperature for this study was kept at $80^{\circ} \mathrm{C}$ for both the experimental work and the 827 simulation. The detailed boundary conditions and zones used in the simulation work are shown in 828 Tables A3 - A5. The different simulation runs conducted for the separate designs required different 829 times for convergence to occur. From literature [35] more time is required for convergence to 830 occur at higher flow rates than at lower flow rates due to the fact that the low flow rate involves 831 the Stefan-Maxwell equation (Full multicomponent diffusion method) which is used in the 832 simulation instead of the Fick's law (Dilute approximation method) that is used for high flow rates 833 thus making the computational model more complex with the values set for under-relaxation 834 factors in Fluent being reduced to enable the calculations to reach stability.

835 In order to confirm convergence of simulations in this study, an approach similar to that used by 836 Arvay et al [36] is used. In their work, they reported that using the residual monitoring alone was 837 not enough to confirm convergence of the simulations and another indicator such as confirming 838 the consistency of the calculated voltage and comparing the current calculated from the amount of 839 the consumed fuel mass with the boundary current is required.

840 Table A3: Boundary zone assignment

\begin{tabular}{lll}
\hline Anode inlet & Inlet - anode & Mass flow inlet \\
\hline Cathode inlet & Inlet - cathode & Mass flow inlet \\
\hline Anode outlet & Outlet - anode & Pressure outlet \\
\hline Cathode outlet & Outlet - cathode & Pressure outlet \\
\hline Anode terminal & Terminal - anode & Wall \\
\hline Cathode terminal & Terminal - cathode & Wall \\
\hline Anode flow field & Ch - a & Wall \\
\hline Cathode flow field & Ch $-\mathrm{c}$ & Wall \\
\hline Anode current collectors & Cc - a & Wall \\
\hline Cathode current collectors & Cc $-\mathrm{c}$ & Wall \\
\hline Anode gas diffusion layer & Diff-a & Wall \\
\hline Cathode gas diffusion layer & Diff-a & Wall
\end{tabular}


842 Table A4: Boundary conditions

\begin{tabular}{llll}
\hline Boundary conditions & Type & Value & Unit \\
\hline Anode Inlet & Mass flow inlet & $6.0 \times 10^{-7}$ & $\mathrm{Kg} / \mathrm{s}$ \\
\hline Cathode Inlet & Mass flow inlet & $5.0 \times 10^{-6}$ & $\mathrm{Kg} / \mathrm{s}$ \\
\hline Anode - outlet & Outlet Pressure & $200000(2 \mathrm{bar})$ & Pascals \\
\hline Cathode - Outlet & Outlet Pressure & $200000(2 \mathrm{bar})$ & Pascals \\
\hline Anode - Wall & Wall & No slip & - \\
\hline Cathode - Wall & wall & No slip & - \\
\hline
\end{tabular}

844 Table A5: Zone assignments

\begin{tabular}{|l|l|l|}
\hline Anode catalyst layer & Catalyst - anode & Fluid \\
\hline Cathode catalyst layer & Catalyst - cathode & Fluid \\
\hline Anode flow field & Ch - anode & Fluid \\
\hline Cathode flow field & Ch - cathode & Fluid \\
\hline Anode gas diffusion layer & Diff - anode & Fluid \\
\hline Cathode gas diffusion layer & Diff - cathode & Fluid \\
\hline Membrane & Mem & Fluid \\
\hline Anode collector & cc- anode & Solid \\
\hline Cathode collector & cc- cathode & Solid \\
\hline
\end{tabular}

846 To prevent divergence in the calculations and water saturation, the source term value and the water 847 saturation under relaxation factor were kept low and this made the convergence of the water 848 saturation value very slow. It was observed that after more than 1500 iterations, the voltage and 849 current usually converged but the water saturation value took longer time before converging when 850 the source term and water saturation under relaxation factors were kept between 0.7 and 0.05 .

851 Another approach suggested by Iranzo et al [38] was also considered for monitoring convergence.

852 This is based on monitoring the average value of the membrane water content and water saturation. 
853 The solution procedure utilized the Semi-Implicit Method for Pressure Linked Equations 854 (SIMPLE) algorithm. This algorithm is a guess and correct method in which the pressure and 855 velocities were calculated and updated in all the iterations.

856 For a well refined computational grid, the speed with which the solution will converge becomes 857 fast and the algebraic multigrid (AMG) was also used to help with the convergence process. The 858 second order upwind solver discretization scheme was used in the simulations.

859 The open circuit voltage was set at $1.2 \mathrm{~V}$. The anodic and cathodic electrode zones were clearly 860 defined in the mesh and named as shown in Table A5 above. The active area of the fuel cell was $86125 \mathrm{~mm}^{2}$. With the exception of the current collectors for each electrode of the fuel cell, all other 862 parts were defined as fluid zones. The mathematical description of the mass flow rate is shown in 863 Eq. A23.

864

$$
\left[\eta_{\text {reactant }}\right]=\frac{i A}{n F}
$$

865 where $i$ is the current density, A is the active area of the PEMFC which is $25 \mathrm{~mm}^{2}\left(0.0025 \mathrm{~m}^{2}\right), n$ 866 represents the various oxidation numbers for hydrogen and oxygen which are 2 and 4, 867 respectively, and F is the Faradays' constant which is $96,485 \mathrm{C} \mathrm{mol}^{-1}$.

868 The mass fractions of the species at the inlet of the anode were set to 0.8 for hydrogen and 0.2 for 869 water. The mass fractions of the species at the cathode inlet were set at 0.2 for oxygen and 0.1 for 870 water. The operating pressure and temperature for the entire simulation for all the humidification 871 conditions were maintained at 2 bar and $353 \mathrm{~K}$, respectively.

872

873 


\section{Appendix B: Experimental Validation of Simulation Results}

875 The experimental results from this study as well as other earlier reported results from Cheng et al.

876 [40] were used to validate the results obtained from the simulation model developed in this study.

877 The parameters used in the laboratory experiment were the same as those used in the CFD 878 simulations.

879 The fuel cell used in the experiments is a one cell stack PEM fuel cell made of Nafion membrane.

880 The surface area of the fuel cell (active area) was $25 \mathrm{~cm}^{2}$ with a thickness of $27 \mu \mathrm{m}$ and a platinum 881 catalyst layer loading of $0.3 \mathrm{mg} \mathrm{Pt} / \mathrm{cm}^{2}$. Pure hydrogen is used as fuel supply and this was provided 882 by a hydrogen generator. A flow meter was used to determine the flow rate of the gas and the 883 supply of the hydrogen to the fuel cell was in dead end mode as shown in Fig B1. It implies that 884 all the hydrogen supplied was assumed to be consumed by the fuel cell.

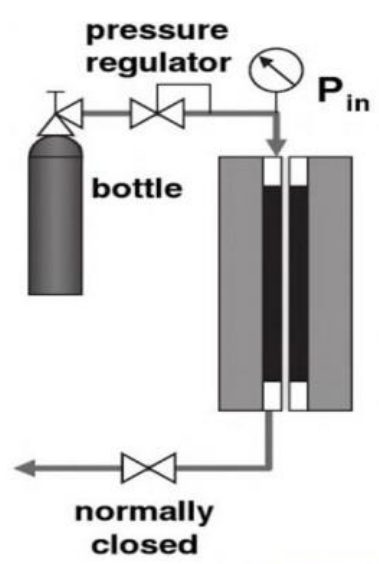

Fig. B1. Dead end mode (Rate of hydrogen supplied is equal to rate of hydrogen consumed To keep the hydrogen gas constantly pressurized, a valve was attached to the anode region of the fuel cell and this valve was often opened to allow the by-product of the electrochemical reaction to leave the fuel cell. The fuel cell used was air breathing and it is shown in Fig. B2.

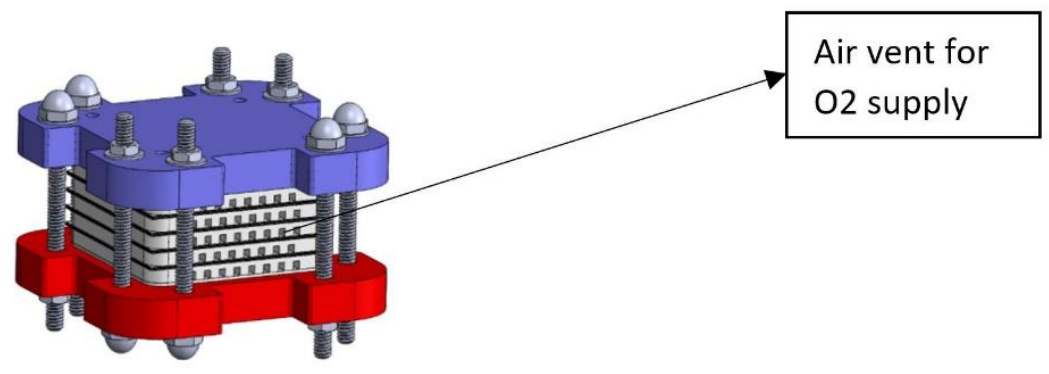


Fig. B2: Air channels for oxygen supply.

892 A fan was attached to the cell to help in cooling and also functioned as oxygen (air) supply to the 893 fuel cell. The experimental set up is shown schematically in Fig. B3 and Fig. B4.
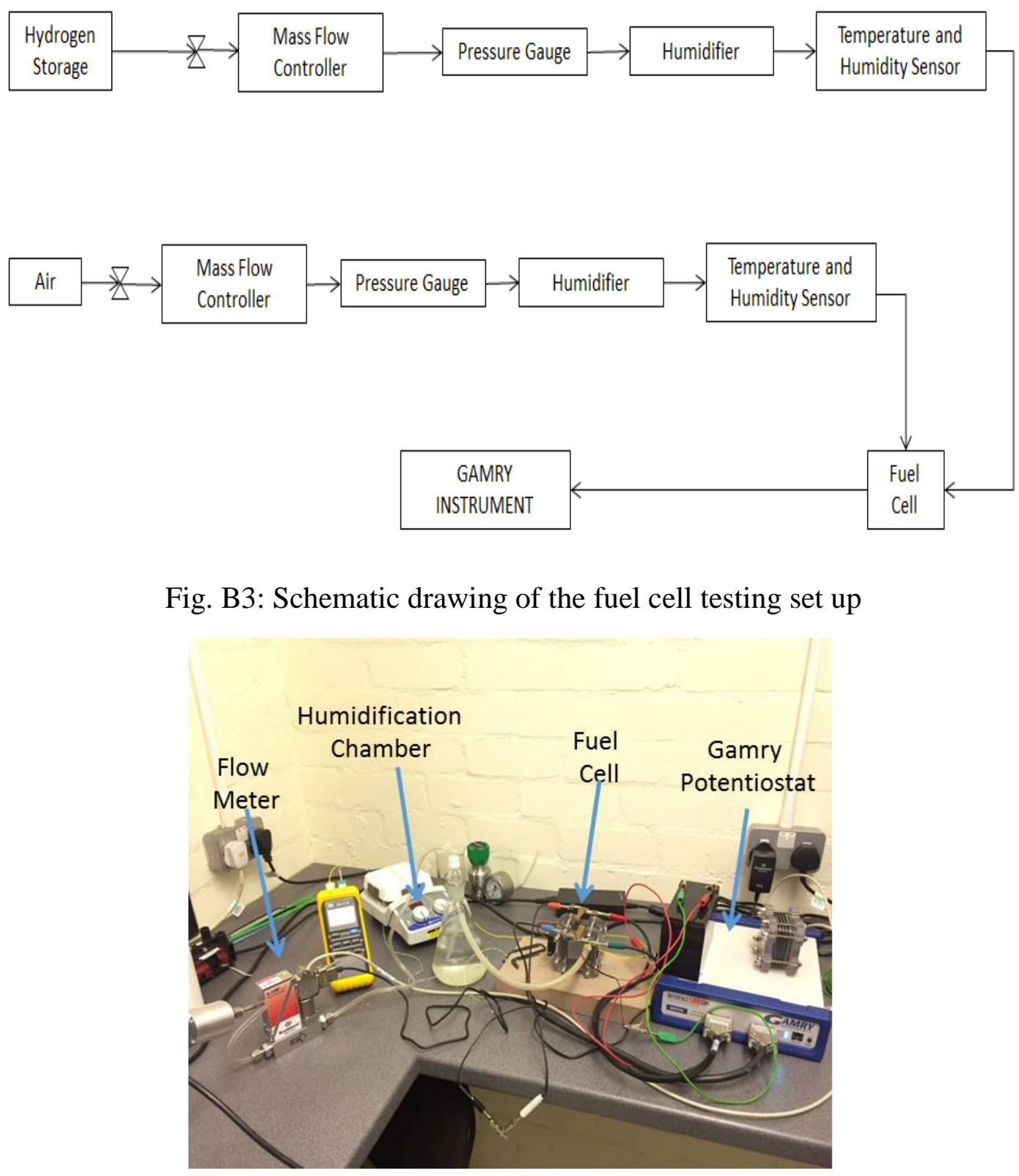

Fig. B4: Experimental set up showing the various connections and hydrogen generator.

898 The setup consists of a hydrogen generator for supplying pure hydrogen to the fuel cell through an 899 electrolytic process. The pressure of the hydrogen leaving the hydrogen generator was controlled and kept constant. The hydrogen gas was then channelled through a flow meter that measured the 
901 gas flow rate. The hydrogen was then humidified by passing it through a humidification chamber 902 as shown in Fig. B5.

903

904

905

906

907

908

909

910

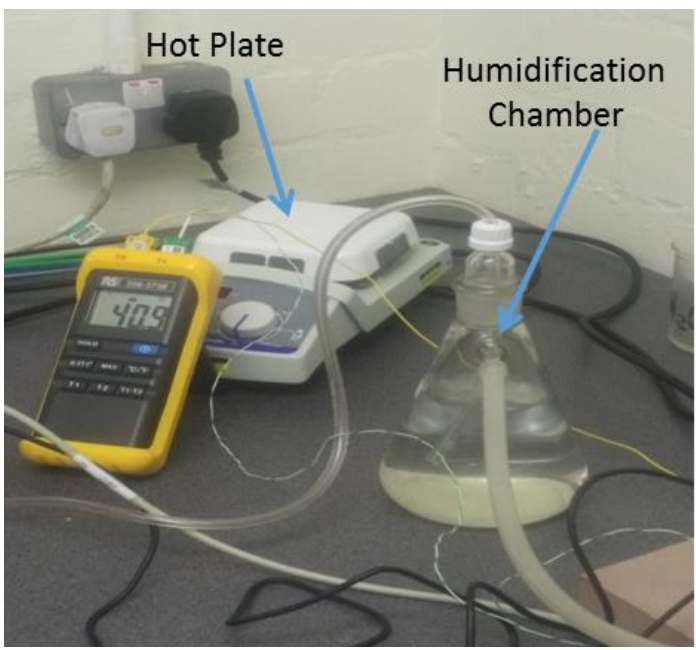

Fig. B5. Humidification chamber.

A Gamry potentiostat was used to determine the characteristic performance of the fuel cell and a thermocouple was attached to the fuel cell to measure its operating temperature. The humidification chamber was filled with water and the temperature of the water was manipulated using a hot plate as shown in Fig. B5. 